\title{
REPORT ON A MISSION TO PAKISTAN AND AFGHANISTAN
}

\section{7-27 November 1990}

to assess the malaria situation in Afghanistan with a special view to returning Afghan retugees

by

Allan Schapira' and Jan Rozendaat ${ }^{2}$ 


\title{
WITH COMPLIMENTS FROM
}

\author{
A R I C
}

ACBAR Resource E Information Centre 


\section{REPORT ON A MISSION TO PAKISTAN AND AFGHANISTAN 7-27 November 1990 to assess the malaria situation in Afghanistan with a special view to returning Afghan refugees}

by

Allan Schapira ' and Jan Rozendaal ${ }^{2}$ ${ }^{1}$ Medical Officer, Malaria Unit. Division of Control of Tropical Diseases,
WHO, Geneva, Switzerland

2

Tropical Diseases, WHO, Geneva. Switzerland Unit, Division of Control of 
From Allan Schapjra, MAL through Chief, Our ref.

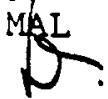

To Chief, REL

Attention

Your ref.

Originator
Subject MALARIA MISSION TO PAKISTAN AND AFGHANISTAN, NOVEMBER 1990

Please find enclosed the report on the above mission, requested by your unit in 1990. The delay in the production of this report, which is due to the lack of secretarial assistance as well as unforeseeable circumstances is very much regretted. Since the mission was requested by REL, we trust that you will undertake its distribution to interested entities, such as WHO field office, Peshawar, WRs Pakistan and Afghanistan, EMRO and UNHCR, at your discretion.

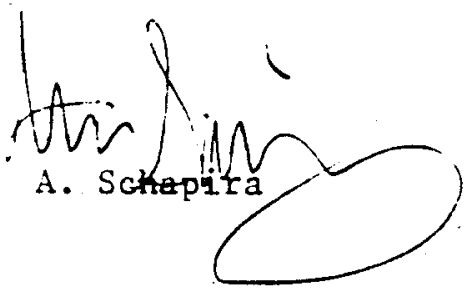

cc. Director, CTD

Associate Director CTD

Chief, OPR

Chief, MAL

Dr J. Rozendaal, OPR

ENCL : (1) 


\section{LIST OF CONTENTS}

ABBREVIATIONS

PREFACE

ITINERARY

INTRODUCTION

Terms of reference

History

Malaria and its control in Afghan Refugee camps in Pakistan

Malaria and its control in Afghanistan

OBSERVATIONS AND FIELD VISITS

Afghan Refugee camps. North West Frontier Province. Pakistan

National Institute for Malaria Research and Training, Lahore

Kunar Province, Afghanistan

Health services provided to Afghanistan via Pakistan

CONCLUSIONS

The malaria situation of Afghan Refugees in Pakistan

Options for malaria control in Afghanistan via Peshawar

RECOMMENDATIONS

ACKNOWLEDGEMENTS

REFERENCES

ANNEXES

Annex 1:Data from AR camps, NWFP

Annex 2:Data from National Malaria Control Programme, Afghanistan

Annex 3:"Green-book data" from Afghanistan

Annex 4:Laboratory activities in Afghanistan supported from Peshawar

Annex 5:Proposed guidelines for the treatment of malaria in Afghanistan in areas not covered by the National Malaria Control Programme

Annex 6:Outline protocols for operational research

Annex 7:Map 


\section{ABBREVIATIONS}

$\begin{array}{ll}\text { AR } & \text { Afghan Refugees } \\ \text { API } & \text { Annual Parasite Incidence (calculated per } 1000 \text { population) } \\ \text { ARC } & \text { Austrian Relief Comittee } \\ \text { BHU } & \text { Basic Health Unit } \\ \text { CTD } & \text { Control of Tropical Diseases Division. WHO HQ } \\ \text { ERO } & \text { Emergencyand Relief Operations Division. WHO HQ } \\ \text { FO } & \text { WHORelief Unit's Field Office. Peshawar } \\ \text { FSMO } & \text { Field Supervising Medical Officer, under PDH } \\ \text { IMC } & \text { International Medical Corps } \\ \text { IIRO } & \text { International Islamic Relief Organization } \\ \text { IRC } & \text { International Rescue Committee } \\ \text { MAL } & \text { Malaria Unit. CTD Division. WHO HQ } \\ \text { MCP } & \text { Malaria Control Programme } \\ \text { ML } & \text { Mid-level health worker } \\ \text { MSF } & \text { Medecins Sans Frontieres } \\ \text { MSH } & \text { Management Sciences for Health } \\ \text { MTA } & \text { Aide Medicale Internationale } \\ \text { NGO } & \text { Non-governmental Organization } \\ \text { NIMRT } & \text { National Institute for Malaria Research and Training } \\ & \text { (Lahore) } \\ \text { NWFP } & \text { North-West Frontier Provinces } \\ \text { OPR } & \text { Operational Research Unit. CTD Division. WHO HQ } \\ \text { Rp. } & \text { Pakistani Rupee: Rp. = approx. O.03 US\$ } \\ \text { REL } & \text { Relief Unit. ERO Division. WHO HQ } \\ \text { PCD } & \text { Passive Case Detection } \\ \text { PDH } & \text { Project Directorate for Health (of Government of Pakistan) } \\ P . f . & \text { Plasmodium falciparum } \\ \text { P.v. } & \text { Plasmodium vivax } \\ \text { UNHCR } & \text { United Nation's High Commissionerfor Refugees } \\ \text { UNOCA } & \text { United Nation's Coordinating Agency for Afghan Refugees } \\ \text { URTI } & \text { Upper Respiratory Tract Infection } \\ \text { WR } & \text { WHO Country Representative } \\ \text { WRC } & \text { Welfare and Relief Committee for Afghan Refugees } \\ & \end{array}$


The central aim of this report is to assess the malaria situation in Afghanistan and Pakistan so as to obtain a basis for recommendations to WHO's Field Otfice in Peshawar regarding possible measures to reduce the malaria risk in the populations living in Atghanistan outside the areas controlled by the Government in Kabul. The malaria situation of this population hias -rightly - been a cause of concern. because of the potential mass repopulation of rural areas with refugees coming from widely different areas, some possibly having lost all immunity to malaria. others carrying heavy parasite loads.

In relation to this central objective, our mission was hampered by two factors: (a) It took place after the end of the transmission season in Afghanistan: and (b) it was impossible to spend more than 4 out of 20 work-davs inside Afghanistan. More time than was absolutelv essential was theretore spent on field work in Pakistan. We have chosen to present all our observations. being fully aware that many of those obtained in Pakistan may be seen as relatively minor supplements to the long-term studies. reported by the PDH, Dr M.Bouma. MSF and Dr de Zulueta. UNHCR consultant.

The reader who wishes to concentrate on Afghanistan mav thus skip the first part of the chapter "Observations/Field visits". The first part of the chapter "Conclusions" brings comments and suggestions related to malaria control for Afghan refugees in Pakistan, focusing on the possibilities of applying pyrethroid impregnation techniques, thus responding to de Zulueta suggestion of a consultancy with specialized knowledge in this field (3). The second part of this chapter summarizes our observations regarding Afghanistan.

The chapter "Recommendations" focuses exclusively on the measures that may be applied to Afghanistan through "cross-border operations". This chapter includes the following captions:"1) Strengthening the laboratory network:"(2) Strengthening surveillance:"(3) Enactment of a drug policy; $\checkmark(4)$ Operational research on vector control (insecticide impregnation

$\{$ techniques) and use of drugs for treatment and prophylaxis: $(5)$

Establishment of a malaria action programme based at WHO FO. In some ways these recommendations differ from malaria control policy guidelines adopted by the National Institute of Malaria and Parsitology, Kabul, and by the Project Directorate of Health working with Afghan Refugees in Pakistan. This does not reflect differences of opinion, but rather the unusual social and operational circumstances of the area we are dealing with. 


\section{ITINERARY}

Wednesday. 7.11.1990. Islamabad

Met at airport by Dr Rudv Coninx. Chief of WHO Field Office. Peshawar.

Meeting with Dr Al Tawil. WHO Representative. Pakistan.

Meeting with Dr Mujaheed. Director. and Dr Hashim. epidemiologist.

National Directorate of Malaria Control.

Thursday. 8.11.1990. Peshawar

Meeting at WHO Field Office with Drs R. Cuninx. Turiq A cim and Win

(WHO), Dr Joe Caragar. UNHCR, Dr Menno Bouma and Mr Dominique Ducornez.

Meeting at

Superintendent.

Meeting at PDH Malaria Referral Laboratory. supported by MSF with Dr

Bouma and Mr Naeem Durrani. Laboratory Manager.

Saturday. 10.11.1990, Kohat District

Field visit accompanied by Drs Win. Aziz and Bouma and Mr Ducornez.

Visit to laboratory at FSMO Office at District Headquarters. Visit to

Darsamand Village.

Sunday 11.11.1990. Kohat Distr.

Visit to laboratory at IRC Field Office in Hangu.

Meeting with Dr Zafer Mohammad. Medical Coordinator for IRC and Dr Tila

Ahmedzai, asisatnt medical coordinator.

Monday, 12.11.1990, Yakka Ghund

Field visit to Yakka Ghund ref ugee camp, Mohmand Agency. Meeting with
Medical Off icer, Dr Shamshir.

Tuesday, 13.11.1990. Mardan District

Meeting with FSMO, Dr Mushtaq Ahmed and Dr Zamani. Medical Officer.

Field visit to Kagan. Jalala and Aza Khel refugee camps and Mardan

Distrct Headquarters Hospital.

Thursday, 15.11.1990, Islamabad

Participation in WHO seminar on health sector strategies and activities forAfghanistan (A.S.) entomologist (J.R.)

Friday, 16.11.1990, Lahore

cont, (J.R.) 
Saturdav. 17.11.1990. Luhore contd. (J.R.)

\section{Peshawar}

Discussions with Dr Oayum. WHO Ficld Officer and Dr Bouma. Visit to

Sunday, 18.11.1990. Peshawar

Meeting at NWFP Provincial Malaria Control Division with Dr Mohammad

Iqbal. Assistant Director. Mr Mlurtaza Khan. Malaria Superintendent. Mr

Meeting withez. Assistant entomologist and Mr Abdul Aziz.

Meeting with Dr Philippe Truze. Avicen.

Meeting with Dr Todd Petersen. IMC.

Malaria Control Programme.

Monday 19.11 to Thursday 22.11.1990 Field visit to Kunar Province,

Afghanistan, accompanied by Drs T. Azim and Daud. WHO FO.

Monday. 19.11.1990.

Visit to Asadabad Hospital. Meeting with Dr Mohammad Aslam.

Tuesday, 20.11.1990)

(contd.) - Meeting with Mr Mohammad Jan, laboratory technician.

Field visit to Asmar. Visit to Asmar District Health Centre. Meeting

Visic co Nochilf Abdul Haj.

Wednesday, 21.11.1990

Meeting in Asadabad with Mr Abdul Qader. Commissar. Salafi Command.

Field visit to Nangalam. Visit to Nangalam IIRO Clinic. Meeting with Mr
Sahib Reda, ML.

Thursday, 22.11.1990

Field visit to Khas Kunar.

Visit to Khas Kunar clinic. Meeting with Mr Khan Agha. ML.

Friday, 23.11.1990, Dere Ismail Khan

Meeting with FSMO, Dr Sarfaraz

Tank, S. Waziristan.

Visit to Christian Hospital. Meeting with Dr Ulla Schmidt.
Field visit to refugee camp.

Saturday, 24.11.1990, Wana, South Waziristan

Field visit to refugee camp in tribal area

Sunday, 25.11.1990

Return from Wana to Peshawar.

Monday, 26.11.1990, Peshawar

Telephone discussion with Dr Shon Campbell, MSF, Belgium.

Final meeting with Dr Rudy Coninx.

Debriefing of WHO Field Office. 


\section{Terms of reference}

A mission to Pakistan with regard to the malaria situation by a staff member from the Malaria Lnit of CTD was requested in July 1990) by the Relief Programme of the Division of Emergency Relief Operations (ERO/REL). The terms of reterence were formulated as follows:

- To visit Peshawar and NWFP and discuss the malaria situation with personnel involved in malaria control:

- To make a visit inside Afghanistan. (Kunar and Paktika) to assess local conditions. status of health systems. laboratories. treatment practices etc..:

- To assess the malaria situation as a public health problem:

- To attend a meeting with all local WHO partners as a facilitator for technical discussions on the ISSHC:

- To advice on which measures to take:

- The consultant should prepare a meeting during three or four weeks and prepare a report upon completion of the assignment."

The Malaria Unit (MAL) responded to the request in September. During several meetings between REL and MAL in September and October. the background was clarified.

The request originated from WHO's Afghanistan Field Office in Peshawar. North West Frontier Province, Pakistan. Under the umbrella of UNOCA, this office cooperates with other UN agencies and numerous non-governmental organizations on "Operation Salaam", a broad effort aiming at improving the conditions for repatriation of Afghan refugees from Pakistan and Iran. Several of these agencies, concerned about the malaria situation in Afghanistan and its possible impact. found that an assessment of this problem was warranted with a view to possible intervention.

In 1989. two missions to the refugee camps had been carried out for UNHCR by Dr Julian de Zulueta. a former WHO malariologist, who had recommended, among other things, that the area be visited by an expert in pyrethroid impregnation techniques. Fortuitously, it was possible to recruit an entomologist with this qualification for the mission reported here.

\section{History}

Since 1978, large numbers of Afghans have fled the war in their country to Pakistan and Iran. Inside Afghanistan. massive destruction of villages, and infrastructure has taken place. It has been estimated that out of the 1979 population of Afghanistan of 15.5 million, 1 million have lost their lives because of the war; 1.5 million have become dislocated and $31 / 4$ million live as refugees in Pakistan. A smaller number has fled to Iran.

During the 1980's aid has been given to the Afghan refugees by various NGOs and UN organizations. Among the UN organizations. the main provider of humanitarian including medical aid to the refugees is UNHCR. The task of the WHO Field Office in Peshawar is mainly to improve health 
conditions inside Atghanistan $-\delta$ -

collaboration with the Govern through cross-border operations and

is the principal provider of health in Kabul. The Government of Pakistan

Pakistan. A special institution thased to the Afghan Refugees in

Directorate for Health (PDH) has in Peshawar. the Project

Malaria and its control in the Afghan refugee camps in Pakistan

Since 1983. PDH runs a malaria control programme in the Afghan refugee camps under the aegis of the National Malaria Control Programme
of Pakistan. The official policy of the National Programme is to keep levels of
transmission low by focal spraying with malathion once a vear. The total
consumption of Malathion is now approximately consumption of Malathion is now approximately 1000 ton/year. Monitoring is based mainly on PCD. which has indicated a gradual increase during the last few vears. In 1989 . the national A.P.I. was $8.5 / 1000$ persons, PCD, but increased import of a possible explanation. Although the from Afghanistan is also considered culicifacies and $A$. stephens the two main vectors $A$. areas. malathion spraving still seems resistance to malathion in some prevalence of $P$. $f$. has been increasing to operationally effective. The vivo investigations by NIMRT (NWFP) in 1989 show rates of in Vehari (Punjab) and Mohmand Agency majority ( $80-90 \%)$ of resistant strainswere RI (Ib). The great The programme in the refuge camps is strongly supported by funding
from UNHCR. Since 1988 a Dutch parasitologist, Dr Menno Bouma. MSF
Holland. has acted as permanent Holland. has acted as permanent technical adviser to this Programme, in particular, the laboratory network. The Malaria Referral Laboratory in Peshawar acts as the reference laboratory of the PDH control programme; in addition. it trains microscopists in malaria diagnosis, also for health care units in Afghanistan.

In 1989, two short-term consultancies to the Afghan refugee camps were carried out for UNHCR by Dr Julian de Zulueta. The support from for early 1991 .

The malaria situation in the Afghan refugee camps has been described in depth in Dr de Zulueta's two reports $(2,3)$. In brief, malaria seems to be transmitted in all the Afghan refugee camp areas. Transmission of $P$. falciparum trancmis March to April until October-November: surprisingly, seems to continue starts in June-July and, somewhat

and $A$. stephensi. higher in Afghan refugee camps of malaria is generally somewhat (Annex 1). In part, this mav be than in neighbouring Pakistanivillages importation from Afghanis explained by more effective PCD and by 
-4 -

retugee population $(t)$ can no longer be invoked as an explanation. There have been no marked fluctuations in transmission in the Atghan retugee areas during the latter years apart from some increase in the incidence of $P$. falciparum.

In 1988. a total number of 85.625 intections were detected by the PCD in the registered Afghan refugee population of 3.252.686 (API 26.3 per 1000 ). Of these infections, approximatelv $15 \%$ were $P$. f. It was recommended by de Zulueta (3) that malathion spraying should be continued only in areas where both vectors were known to be sensitive. and that fenitrothion should be used in areas with an increasing incidence of $P$.f.. Prompt treatment according to well-established dosage schedules with chloroquine + primaquine (dosage according to species) as first line treatment was recommended as the main method of malaria control. Finally, it was proposed that trials of permethrin impregnated bednets and tents be carried out in selected A.R. camps.

\section{Malaria and its control in Afghanistan}

Traditionally, malaria is an important disease problem in Afghanistan. The distribution is focal, river vallevs and irrigated lands being the areas mainly affected. In most of the country. both $P$.v. and $P$.f. may be transmitted. although the transmission season is relatively short (July-October).

A National Malaria Control Programme based on DDT intradomiciliary spraying (anti-larval operations in towns) was started in 1953. The initial effects were dramatic: previously uninhabitable areas were opened for agricultural exploitation (6). In 1956, malaria eradication was adapted as the goal. In 1968,7.9 million people were covered by the eradication programme; 2.6 million of these had entered the consolidation phase. In 1970, a change in the vector situation became apparent: the original (at least putative) main vector, $A$.

superpictus, had been virtually eradicated. but replaced by the endophilic A. stephensi and $A$. culicifacies and the exophagic and exophilic $A$. hyrcanus and $A$. pulcherrimus. Part of the vector population developed resistance or behaviouristic avoidance. Where necessary, a change was made from DDT to malathion. with good results. In towns, temephos replaced diesel oil for larviciding. In the problematic rice-growing areas in the north, especially Kunduz, the larvivorous fish, Gambusia, was deployed with success (7).

During all the years, the antimalaria activities were directed by the National Institute for Malaria and Parasitology, Kabul, with strong support from international organizations and foreign countries. Despite setbacks, deficiencies and numerous constraints and obstacles, the Afghan MCP was generally considered relatively effective and efficient, having a strong national academic staff and a steadily increasing network of PCD laboratories (240 in 1979). During the late 1970's, the number of recorded infections in the country per yearvaried between 40,000 and 80,000 (API $2.5-5$ per 1000 ) of which only about $1 \%$ were P.f. (8).

Since 1980, the war in Afghanistan has led to a progressive breakdown of all malaria control activities. Depopulation of fertile river valleys and increased population density in towns could tend to reduce the incidence of malaria but a breakdown of irrigation systems 
$-10$.

could cause an increase of potential anopheline breeding sites. Figures provided during the latest vears by the National Institute for Malaria monitoring system has had only partially representative. since the started $(9-10)$.

In 1988. the total number of infections recorded was 379,000 (theoretical API 36/1000). Data from 1987 give an idea of the distribution of cases. although it must be taken into account that they are particularly incomplete for peripheral areas (Annex 2). API levels Region) and Taloquam (Nord in Jalalabad. Laghman and Kunar (East coverage of the PCD svstem the SPR gion). Considering the unequal risk. Based on this criterion, the SPR might give a better indication of Region. and Dilaram in areas most atfected. Indeed South West Region would be considered the years in Jalalabad and Laghman emics have been recorded in recent serious malaria outbreaks in the units (10). However, the potential for low number of cases there may south is obvious, considering that the proportion of infections caused mainly be due to depopulation. The approximatelv $1 \%(9)$, but it is by $P$. $f$. has remained at relativelv rapid in the south (Helmacted that the increase is Chloroquine-resistant $P$. (Helmand and Kandahar) (10). but an epidemiological study been detected in Atghanistan (10), resistance has been found in a this is not on record. "Fansidar" personal communication). 
Afghan Refugee camps in North West Frontier Province

\section{Kohat District}

Approximately 199.000 refugees live in the Kohat district. Health care is mainly provided by an NGO, the IRC which also has its own laboratory facilities. It provides "integrated aid" to the refugees including basic health care, income generating activities, pit latrines. shallow wells and source reduction for malaria control.

Health services are provided througha network of BHUs, supervised by the FSMO. Some BHUs have laboratories: the others send slides to the District Laboratory. By and large, the guidelines for malaria diagnosis, treatment and notification are followed, and the three basic drugs, chloroquine. primaquine and "fansidar" are present where needed. The population seems to be satisfied with the malaria treatment facilities. and the compliance with controls is usually $50 \%$ or above. This situation prevailed at almost all the health care units visited by us in NWFP. The standard of the laboratories was generally very satisfactory. To a large extent this can be ascribed to the continuous quality checking and refresher training activities exercised by the paradigmatic reference laboratory in Peshawar.

The IRC data (Annex 1) show a steep increase in $P . f$. incidence during 1990, despite house spraying with fenitrothion in early September. (Fenitrothion was used because one of the supposed vectors. A. stephensi, is resistant to Malathion).

Two family compounds were visited in Darsamand and two in a nearby village. Each included living quarters for the family members. store rooms, kitchen and cattle sheds. No traces of spray deposits were observed, except in one case on the roof timber. The houses were all said to have been replastered since the last spraying. The replastering is said to be done $3-4$ times a year to repair and cover cracks in the mud-brick walls and to beautify the houses for special ceremonies. Any relation with the spraying was denied.

The houses were compact with thick walls, a door opening and one or a few small window openings. Eaves openings were generally absent or filled up temporarily during the winter months. Because of the lower temperatures and the wind, the window openings were closed off by plastic in some houses. The plastic is removed in spring when temperatures become higher. The windows in a few houses were screened with mosquito gauze. Searches with a torch in living rooms and cattle sheds did not yield any anopheline mosquitoes. The inhabitants said that mosquitoes are a problem when they sleep outdoors from March to October. Mosquito nets are not used.

During summer, breeding of anophelines was recorded in pools in the riverbed and in rain-filled ponds or borrow-pits in or near the village. During our visit only a few larvae of Anopheles culicifacies and $A$. maculatus were found in ponds with clean water in the river bed. The few pools in the village were dirty and did not contain any larvae. 
Yakka Ghund is a camp with a registered population of about 18.000 and an unregistered population of 7.000. A BHU manned by a Medical Officer and supporting staff provides medical services. The high malaria rates were investigated by De Zulueta $(2,3)$. P.f. occurred in all age groups and in both sexes, suggesting local transmission. In both years the incidence of $P$. $v$. peaked in September-November and that of $P . f$. in November-January (Annex 1$)$. The continued increase of malaria transmission after the malathion sprayrounds in 1988 and 1989 suggests resistance of the vectors to the insecticide.

Collections of indoor resting mosquitoes in Yakka Ghund in October 1989 showed that $A$. stephensi was predominant with $67.8 \%$ of the total. A. subpictus was second with 28.4\%. A. culicif acies being relatively rare $(2.5 \%)(3)$. A. culicifacies is generally considered the primary vector of malaria in Pakistan but the role of $A$.

stephensias a vector has recently been reviewed and confirmed by Parvez (1988) and this species might be an important malaria vector in NWFP. Susceptibility tests revealed that $A$. stephensi in Yakka Ghund is highly resistant to malathion $(1 \mathrm{~b}, 3)$. It was therefore recommended to spray fenitrothion instead (3). This was carried out in August 1990, but nonetheless. the incidence rose during the following months. Supervisory statf claimed that the spraying coverage had been close to $100 \%$ but we observed that some living rooms had not been sprayed, which was confirmed by the house owners. Extremely poor adherance of the insecticide particles to the mud-plastered walls might be one explanation. Outdoor resting of the mosquitoes and continued outdoor transmission until the end of October (when people start to sleep indoors) might be an additional explanation.

Since October 1990 a source reduction campaign is carried out eliminating all stagnant water collections in Yakka Ghund. Borrow-pits near most houses were filled up or connected with drainage canals. However, during our visit many (dry) borrow pits were observed which are likely to become breeding sites during the rainy season in July-August. Anopheline breeding sites still appeared to be available in pools in the almost dry riverbed near the village. Clean water collections contained a few $A$. stephensi and $A$. culic if acies larvae, while in organically polluted water large quantities of 4 . subpictus were collected. It seems that breeding sites are available in the riverbed when the water level is low. When these sites disappear in the rainy season, alternative sites become availabe in the many borrowpits near most of the houses.

Two family compounds were visited and searched for indoor resting anophelines. Traces of fenitrothion were only observed in one living room out of three. In the cattle shed, $A$. culicifacies, $A$. subpictus and $A$. turkhidi were collected.

Local men had been trained as spraymen by malaria supervisors. Their training included special safety precautions for fenitrothion. Apparently this substance was not handled carefully during the spraying activities and several spraymen fell sick. Being paid according to the number of sprayed houses, they asked family members to take over, which probably led to a further deterioration in satety standards as well as quality of the spraying. 
Approximately 3.500 retugees live in Kagan and 12.500 in Baghicha. The villages are situated a few $\mathrm{km}$ from each other in a fertile plain with a high watertable. The area is completely covered with an extensive network of drainage canals and fields with sugar cane. wheat and other crops. Each village has its own BHU which receives supplies from the ARC. A malaria microscopist is based in the BHU in Kagan. Compared to previous vears, the malaria situation has deteriorated considerably (Annex 1).

As in other refugee village, the increase in $P$. $f$. starts late, in September, and peaks in October-November. Most of the positive cases were due to local transmission, but some were imported from the Punjab and from Afghanistan. The relatively high endemicity of malaria was said to be due to the abundance of breeding sites for $A$. stephensi and $A$. culicifacies. In 1987 and 1988. the villages were spraved with malathion twice a year, in July-August and in September. In 1989 only one spray round was carried out and none in 1990. This was explained by the observation of widespread malathion resistance in $A$. stephensi in the Province (3). However, recent susceptibility tests carried out in Mardan district suggest that $A$. stephensi is not resistant to malathion. As an alternative. it was decided by the PDH to spray possible breeding sites with an insecticide. The insecticide. Pesguard $3 / 7$ ULV (Tetramethrin $3 \%$ and d-Phenothrin $7 \%$ ), manutactured in 1982, was obtained from the National Malaria Programme in Islamabad. It was sprayed once in two weeks by special teams with hand compression pumps. It is unlikely that this insecticide has any impact on larval densities because its formulation is designed for ultra low volume (aerosol) applications, and it probably lost its insecticidal effect several years ago.

Entomological observation: We investigated potential breeding sites and found numerous larvae of $A$. subpictus and a few of $A$.

$c u l i c i f a c i e s$ in muddy water in a series of interconnected shallow borrowpits just outside the village, said to be sprayed with Pesguard 6 davs earlier. The presence of $4 \mathrm{th}$ instar larvae indicates that the spraying with Pesguard is ineffective.

In a compound nearby, the living quarters and a cattle shed were searched for anophelines. Numerous specimens were collected, all resting on the roof timbers. The cattle shed yielded more specimens than the human habitations nearby. Most of the specimen were $A$. subpictus but $A$. fluviatilis and $A$. stephensi were also collected.

Observations from Mardan District Headquarter Hospital: About 10-20\% of the hospital's patients are Afghan refugees. Malaria is not more common among these than among Pakistanis. In the Internal Medicine ward, malaria is an important cause of hospitalization; complications are rare, but during the last $2-3$ months. 20 cases of cerebral malaria were admitted. In the Pediatric ward, of 2000 hospitalizations per year, approximately 200 are caused by malaria. After gastrointestinal infection and acute respiratory tract infection, malaria is the most important cause of pediatric hospitalization. 
Wana, South Waziristan Agency (23-25 November 1990)

Wana is a village situated on a plain at about $1400 \mathrm{~m}$ altitude. About 50.000 refugees have settled in the area near Wana and another 30.000 semi-nomadic refugees spend the relatively cool summer months in this area. In the winter they return to their camps in the Punjab. mostly near Mianwali but also near D. I. Khan and Tank. Many of these migratory refugees live in tents although some of them also have houses. In the Wana area, malaria is most frequent among the refugees living in
tents.

Indoor collections of adult resting anophelines in September 1989 yielded $68 \%$ A. stephensi and $32 \%$ A. culicifacies.Both species
were susceptible to malathion and permethrin (3).

In this area, trials of alternative vector control methods were initiated in 1990 by Dr Bouma. The interventions included spraying with permethrin of tents used by the refugees and small-scale trials with permethrin impregnated curtains and mosquito nets. (A full description
of the trial is available in OPR/CTD.) Almost 6000 tents were sprayed with a target dosage of
$0.5 \mathrm{~g}$ permethrin $/ \mathrm{m}^{2}$. This insecticide has low toxicity to humans and
resistance to it has never been reported in the low resistance to it has never been reported in the local vectors. The spraying procedure was different from the standard procedure for residual wall spraying. The tent walls were sprayed from the inward side until the point of run off (full-saturation). As appeared later, this procedure resulted in a low dosage of active ingredient on the surface layer. The inner tent consisted of four layers of cotton and much of the a very low dosage on the inner layed by the outer 3 layers, leaving only mosquitoes.

Application of the standard spraying procedure, resulting in the impregnation of the first layer only, is recommended for future trials. The spraying of the outer tent is not recommended because the space daytime resting outer tent is unlikely to be an important mosquito quantity and a considerable furthermore allows halving the insecticide

An evaluation of the effectiveness of the spraying on malaria transmission is only possible by retrospective comparison. The results
will become available in 1991 .

\section{The bednet trial}

This trial was carried out in a refugee village by randomly selecting 70 households and providing them with impregnated mosquito nets for all family members. The remaining households serve as controls. Because of logistical and other difficulties no entomological observations have been made. The parasitological results of this trial
will become available in 1991 . 
$-15$.

The local mullah. who had promoted the use of the nets through the loudspeakers of the mosque. claimed that the nets were well accepted and used outdoors only during the hot season. By the time people started sleeping indoors the nets would be unnecessary because the mosquitoes would have disappeared because of the cold. When used outdoors, the mosquito nets were suspended from poles attached to the bed or from nearby walls and other objects. In the community at least two persons appeared to have their own mosquito net: the mullah and the teacher. Both nets were large family-size nets made in Pakistan of jute or cotton. The price was said to be 135 rupies (US\$ 4.-).

\section{The curtain trial}

The trial with impregnated curtains was carried out in another village bv spraving available curtaiq material in randomly selected households with $1 \mathrm{~g}$ permethrin $/ \mathrm{m}^{2}$. Some households were, if necessary, also provided with extra curtain material to cover door and window openings. Untreated households serve as controls. Parasite rates in the intervention and control group are not yet available

\section{Traditional methods against biting mosquitoes}

People sometimes burn certain repellent substances on a fire. A method used at night during the summer is the chador. a thin fabric of cotton or svnthetic tibre. about $2.5 \mathrm{~m}$ long and $1 \mathrm{~m}$ wide, wrapped around the body, including the head, to keep off mosquitoes and crawling animals. According to the mullah in Wana and other Afghans, the chador was used by everybody during the summer months and the head was only left uncovered at nights when it was too hot and when there were no mosquitoes. The chador was sometimes also used as a transportation bag for goods to be bought or sold at the market. When the nights are cool, a patoe (thin woollen blanket) is used instead of a chador.

\section{Data from Tank Christian Hospital, S. Waziristan}

Malaria is considered the main cause of admission in adults and children. From April to December 1989,414 of 1378 in-patients had malaria (30\%). Among the malaria patients, at least $213(51 \%)$ had P.f. All ages seem to be equally affected. About $50 \%$ of the patients are A.R. At our visit we saw several children and adults in coma with positive slides. Tank has a population of 49000 . The hospital's catchment population may be about 90000 . If 414 is the number of severe (needing hospitalization) malaria cases in a year, then the vearly incidence would be 4.6 cases per 1000 . This is of course a minimum and indicates that malaria is indeed a public health problem in the area. 
$-16-$

Visit to the National Institute of Malaria Research and Training (NIMRT) in Lahore (15-16 November)

The NIMRT conducts operational research to support the National Malaria Programme and also provides training for malaria microscopists. malaria inspectors, malaria supervisors and other malaria workers. of the NIMRT (1a, lb).

One of the authors (JR), visited Lahore to discuss with Mr Parvez. Head of the Department of Entomology: (a) the possibilities for further (b) the po a future operational research programme in the refugee camps; workers. involved to provide entomological training to future malaria findings in NWFP; (d) available ms in Afghanistan: (c) research preliminar bednet trial conducted by

The institute maintains colonies of various strains of $A$. culicifacies and $A$. stephensi which could be used for bioassay tests in future trials. In addition, the institute could offer assistance for species determinations. susceptibility tests and field work such as human bait collections at night and collections of indoor resting mosquitoes. The NIMRT team would have to be provided with transport and a daily allowance if they have to work in the field.

Training of local, or expatriate malaria staff could be undertaken at the NIMRT, and a special programme could be prepared according to the

Bednet trial in a village in Punjab A preliminary trial with 135 mosquito nets was carried out in a malarious village with rice cultivation at about $60 \mathrm{~km}$ from of the nets were impregnated with $0.5 \mathrm{~g}$ permethrin $/ \mathrm{m}^{2}$. was untreated. According to $\mathrm{Mr}$ Parvez many dead mosquitoes were found on sheets treated nets were efficacious: However. to his opinion the nets are not well an the ground under them. everybody sleeps outdoors in the hot well accepted. In the Punjab until early November, because of the hea trom the end of February sometimes remains above $30^{\circ} \mathrm{C}$ ) and hight may have a psychological bias against the nets of space indoors. People the nets reduce ventilation and education could possibly and that they are suffocating. Health with electricity of ten possessed this attitude. Inhabitants in villages outdoors for extra ventilation 1 or 2 electric fans which are used mosquito problem is very severe to repel mosquitoes. When the a fan was available. Some famere people said they would sleep indoors if family said they used about 30 ies use mosquito coils indoors. One for a full night protection $(2$ coils a year. Two coils had to be used it would be too expensive to nets. This would cost $6 \times 135$ rotect the whole family ( 6 persons) with family with a monthly income $135=810$ rupies, which is too much for a spite of the above objections, of $1000-1200$ rupies (US\$ $45-50$ ). In mosquito net and several pe, some families could show a Pakistan-made one. 
$-17$.

According to $\mathrm{Mr}$ Parvez. housespraving is appropriate and effective in the Punjab. Although most transmission occurs outdoors many mosquitoes rest indoors. especially in cattle sheds and store rooms. The relatively small proportion resting in living rooms could probably be explained by the fact that cattle sheds and store rooms are more humid and cooler while smoke sometimes prevents entry in living rooms.

It seems that the spray deposits are not affected by frequent replastering. Also the plaster is durable and smooth and could provide a better substrate for adherance than is the case in the AR camps in NWFP.

\section{Seasonality of malaria}

According to Mr Parvez the seasonal fluctuations of $P$. $v$. and $P$. $f$. in the Punjab are similar to those in NWFP: a peak for $P . v$. in August-September and a peak for P. $f$. in October-November. One partial explanation could be the higher parasite reservoir of $P . v$. early in the transmission season due to relapses. Another, hypothetical, explanation might be different vectorial capacities of the two vectors $A$. culicifacies and $A$. stephensi for the two parasite species. $A$. culicifacies seems to be a more efficient vector of $P$. $v$. while $A$. stephensi is a more efficient vector of $P$.f. (1). $A$. stephensibiting densities peak in March-April and again in September-October, while A. culicifacies densities peak in July-August. Both species breed in paddy fields and irrigation channels. but $A$. stephensi also breeds in rainwater collections. $A$. culicif acies breeds in the rice fields shortly after they are watered, when the rice plants are still small and $A$. stephensi starts breeding when the rice plants are higher. (It seems that $A$. culicif acies needs open space to deposit the eggs one by one over a large area, which is difficult when the rice plants are taller.) 


\section{Kunar Province,}

General Characteristics

Kunar Province is in Eastern Afghanistan. bordering on Pakistan (NWFP) to the east, Nangarhar (Jalalabad) to the south, Laghman to the west and Badakhshan to the nonth. It is situated between $34^{\circ}$ and 35 approximately 300000 ). The province has 13 lation 147000 (pre-war has approximately 20 villages. The Provis 13 districts. and each district character of a large village the Province capital. Asadabad. has the $10000-15000$. I vilage, the population probably not exceeding road in reasonably good condition. Peshawar in 6 hours by a mountain

The province is traversed from north to south by one of the country's major rivers, the Kunar, which receives several affluents in the province. The altitude of the inhabited parts of the river valleys is between 300 and $1000 \mathrm{~m}$, the mountain peaks reaching $4000 \mathrm{~m}$. Large river valley areas are intensely cultivated with small irrigation systems and terracing. In spring, the water from mountain currents which are filled up by the melting snow is utilized as much as possible for

By and large, houses are constructed of mud-brick, of ten with two or three floors. Animals are of ten stabled in the ground floor. while part of the second floor is a veranda. The roots areflat, and used for
sleeping during summer.

Kunar Province is probably one of the areas in the country that has been under Mujahedin control for the longest period. Until 1988. place, a fambings of houses, fields and infrastructure still took Political authority is divideo evident in all the villages visited. of them being enrolled in garrisonse proportion of men go armed. many equipped with watchtowers.

A good deal of reconstructive work on roads and bridges takes place: one gets a certain feeling of optimism; people are poor, but not will spend days not seeing well-nourished. The visitor to the Province application of purdah. Many men, consider do the rigourous not, spend time in the Province, leaving theing themselves mujahedin or Pakistan.

\section{Health care facilities}

Numerous NGO's have been involved in setting up clinics. One of the most active, the IIRO, has recently withdrawn most of its support from the Province. The WHO Field Office's database, has recorded 42 active (active + inactive + unkovince and 6 non-active. In comparison, 202 South-West region which cown status) facilities are recorded in the workers registered in Kunar is 287 . 8 provinces. The number of health Kunar (90 in the country). 
1. Asadabad Hospital

Sponsor:Afghanistan Nothilfe (German NGO).

Staff: 1 surgeon. 1 dentist. 6 nurses. 1 laboratory technician.

Facilities: Operating theatre. X-ray. in-patient ivard.

Outpatients: About $50-100$ outpatients are seen daily. From July to

November. $50-80 \%$ of these appear to suffer from malaria. It is not possible to take slides from all of these, only $5-10$ per day.

Laboratory: The laboratory technician had been trained in the Kabul High School of Technology in 1971 . His Olympus microscope is in good condition. working on electricity (supplied daily by the hospital generator). The Giemsa staining is of poor quality. Only the thin film is observed. The technician has some notion of species differentiation. The only parasites which he could demonstrate were $P$. $f$. gametocytes in the thin film. In the reports, no distinction was made between asexuals and gametocytes. It was said that earlier in the year $P$.v. had been more prevalent. $P . f$. becoming dominant in October. Treatment: The hospital receives drugs free of charge, incl. 5000 chloroquine tablets per month. This is enough to treat all the presumed malaria patients. Patients who do not respond to chloroquine are treated with quinine tablets, also supplied from Nothilfe.

Slide results recorded in the laboratoryare shown in the following table.

Malaria slides, Asadabad Hospital, 1990

No.slides \%pos.No. pos.

$\begin{array}{lrrr}\text { March } & 80 & 55 & 44 \\ \text { April } & 70 & 39 & 27 \\ \text { May } & 127 & 46 & 58 \\ \text { June } & 71 & 65 & 46 \\ \text { July } & 106 & 57 & 60 \\ \text { August } & 112 & 70 & 78 \\ \text { September } & 152 & 68 & 103 \\ \text { October } & 111 & 56 & 62 \\ \text { November }(<20 / 11) & 62 & 73 & 45\end{array}$

2. Private pharmacy, Asadabad bazar

At Asadabad Hospital we observed a febrile 8 year old child who had been treated the day before in the bazar with an injection of chloroquine, $125 \mathrm{mg}$ (approximately $5 \mathrm{mg} / \mathrm{kg}$ ). Such a treatment would normally cost 5 rupees (although the Afghani is currently in use, the Pakistani rupee seems to be the preferred currency). However, sometimes the private practitioners charge nothing for the treatment until the patient is cured. When this happens, 50 rupies may be charged.

\section{Asmar District Hospital Sponsor: MSH}

Staff: 2 doctors, 1 mid-level health worker, 1 microscopist, clercs and guards. At the time of our visit, one doctor was absent and the microscopist on holiday.

Facilities: 8 beds. (This "hospital" should be considered a health centre). 
Outpatients: $50-120$ are seen -0

in the village. Patients are refarly, although there are other clinics neighbouring smaller villages.

in Asmosis: The microscopist. trained in Peshawar by MTA, has worked most of the fever patien June. a malaria outbreak was suspected but that it was probably a viral had negative slides, so the doctor concluded patients have a slide viral epidemic. As a principle, suspected malaria outpatients have had taken. From July to October, $30-50 \%$ of In August. a French

to study malaria. Carefor ( 1 doctor and 1 biologist) staved for 1 month outpatients. About 238 shide-examination was performed on 260 being negative. During this visit, $P ., 10-15 P . v$. , the remainder training. The doctors are kisit, the microscopist received extra malaria diagnosis verified in that all patients should have their attitude in health workers in the laboratory, and try to instill this collaborate. The result. as admitred byeral clinics with whom they malaria patients sometimes arrived by the doctor interviewed, is that hospitalization. It is the impression that in the disease needing most frequent in Asmar village. One village highintrict, malaria is to be malaria-free. As the microscopist was high in the mountains seems the laboratory. Treatment: Chloroquine tablets. although supplied from MSH are chloroquine-resistance and werients were said to have shown in the bazar. A few patients are arescribed Fansidar, which can be bought great majority are cured, with quinine infusions (diagnalaria. The not rigorous).

\section{Nothilfe Clinic in Asmar (situated about $2 \mathrm{~km}$ from Asmar District}

Sponsor: Afghanistan Nothilfe Staff: One mid-level health worker, has worked in Asmar for two
years.

Facilities: Two beds for emergencies.

Outpatients: 50-60 patients are seen per day. 20-30\% of these are diagnosed clinically as suffering from malaria. The diagnosis is based temperature is verified by thermometer.

patients.
Treatment: Routinely the classical $(4+2)+2+2$ scheme tablets are prescribed, for adults preferred, but is now out of stock. For children, chloroquine syrup is clinic, and taken at home. Patients not responding handed out at the whose symptoms recrudesce are prescribed Fansido chloroquine or adults), which can always be bought in thed Fansidar ( 3 tablets once for worker realized that these patients in the bazar in Asmar. The health the laboratory. However, he said should preferably be diagnosed at laboratory, and the microscopist is of patients do not like to go to the genuine collaboration between the of ten absent. Clearly, there is no supervision.

The well-kept registry bo was notable here as elseok confirmed the health workers information. It groups seem equally affected. However, taking into accountent, all age population is to some extent dominated by adult men, it is still
possible that the incidence is higher in children. 
5. Monogi Clinic, Nangalam (Pech District)

Sponsor:I.I.R.O.. - in the process of withdrawal.

Staff: 2 mid-level health workers. Previously, there were. in addition. one doctor. one microscopist.

Outpatients: From July to September. about 250 patients per month have "malaria". About 10 of these do not respond to chloroquine. They are prescribed Fansidar, which can be bought in the bazar. A few cases with severe/cerebral malaria had been treated with chloroquine infusion. Survey and prophylaxis: In August 1990 a microscopist visited a number of houses. preparing smears from males. Out of 112 slides. 60 were positive, of these 6 showed $P$. $f$. Positives were treated with chloroquine or amodiaquine approximately $25 \mathrm{mg} / \mathrm{kg}$ over 3 davs. Thereat ter the people surveyed were given pyrimethamine $25 \mathrm{mg}$ once a week for 0 weeks. It appeared that people were glad to receive this prophylaxis, and those who received it had less malaria than others. Pregnant women and children under the age of two years did not receive pyrimethamine, because the health workers were worried that it might be harmful to them.

\section{Private pharmacy, Nangalam}

Localization: $10 \mathrm{~km}$ from Nangalam on the road to Asadabad.

Staff: Pharmacist ("M.D."?) not present. Microscopist (son of above) was originally trained by an NGO in Peshawar. He worked for a short time as microscopist in Afghanistan at a non-profit clinic that closed. He is now helping his father, but would like to have a microscope so that he could make some diagnoses.

Facilities: The pharmacy is well stocked with a variety of useful drugs (especially antibiotics) and the usual fancy vitamin preparations and patent medicines. It is well-ordered and tidy in comparison with most non-profit facilitięs seen. The antimalarials in stock are: chloroquine (Resochin ${ }^{R}$ Baver) as tablets and injectable, and Fansidar Roche tablets. 10 tablets of chloroquine cost 5 rupees. 3 tablets of Fansidar cost 9 rupees.

In the bazar in Nangalam. there is supposed to be an additional pharmacy, but it was closed at the time of our visit. Always having bednets in our minds, we noted a tailor, working busily with a hand-driven sewing-machine.

\section{Clinic, Khas Kunar}

Sponsor: IIRO (withdrawing) and WRC

Staff: Two mid-level health workers

Outpatients: During July-August, approximately $70 \%$ of patients have "malaria". In November, $25 \%$ are labelled with this diagnosis. Treatment:Adult patients are treated with chloroquine in correct dosage; this drug is now out of stock, and patients must buy it in the bazar ( 8 rupees for 10 tablets). Patients with severe disease are treated with injectable chloroquine. Primaquine is found on the shelves of this clinic. It was used previously when diagnoses were confirmed microscopically. The clinic looked extraordinarily messy and disorganized, a fact which would probably not increase the villagers' confidence in the very young health workers.

Survey: In July, some house to house surveys were carried out, followed by prophylaxis with pyrimethamine, $25 \mathrm{mg}$ per week. The results were considered good. 
The population's attitudes to, malaria and to health care facilities

In general, adults know that malaria ("malariah" in Pashtun) is a febrile dise ase transmitted seasonally by mosquitos. Knowledge about mosquito breeding habits is not so good. Malaria is considered a major disease problem in Kunar, affecting all age-groups equally. It is believed that the best way to combat the disease is by killing the mosquitoes with intradomiciliary spraying with insecticides, and such action would be strongly welcomed. It was said that a few Mujahedin who have learnt this habit in Pakistan use bednets. Most people doubt that bednets would be popular (it is assumed that the population is generally sleeping outside.

Regarding treatment, there is a strong preference for injections. Despite one health-worker's observation to the contrary, it is the general impression that people like to have their blood examined (one clinic in NWFP receives patients from Afghanistan who prefer to travel the extra distance, because they do not want to be treated for malaria without a proper diagnosis!)

It is quite common for non-profit health care facilities which are known to receive drugs free of charge from various organizations to receive armed clients/patients who will request a certain drug or treatment at gunpoint. This does not happen to private pharmacies. Apparently, private property enjoys a certain respect, while foreign donations are considered fair game.

\section{Entomological observations}

Numerous potential breeding sites were observed in fields and in the river-beds, but none contained larvae. Neither was it possible to find adult mosquitoes inside houses or stables. This fact can be easily explained by the low temperatures at the time of our visit (approaching $5 \mathrm{C}$ in the night). The altitudes of the sites visited were measured $700 \mathrm{~m}$. 
About +3 NGO's are involved with health care in Afghanistan. Considerable effort has gone into training of mid-level workers. but it has not yet been possible to create uniform standards. The training of Basic Health Workers has now been terminated because it is not possible to supervise them.

Drugs are supplied by the various NGO's, but the Swedish Committee for Afghanistan and MSH centralize some of these functions. There is little concerted preventive medicine action. The exception is a clearly vertical vaccination programme run by the French NGO AVICEN. with financial support from EEC. The vaccinators are presently trained only for this purpose, but might with time take on additional tasks related to preventive medicine. Data-collection is now becoming well-organized and centralized. WHO FO maintains a large database on health care facilities and personnel. Collection and consolidation of epidemiological data from health care units is centralized by IMC. These data include malaria cases, usually diagnosed without laboratory support. differentiating by sex and adult/child (Annex 3 ).

The health care units inside Afghanistan, are responsible to their sponsors. There is no hierarchical structure. i.e. no definition of supervisory competence or referral channels. despite the fact that it has long been agreed that this would be desirable.

\section{Training and supervision of laboratory personnel}

For the training of laboratory workers, mainly IMC, IRC and MSF Holland/Belgium are involved, IMC being the coordinator. While generally, too many health workers have been trained under anarchical conditions, it is assumed that more laboratory workers are needed (see Annex 4). The malaria part of the curriculum is taught by the MSF supported referral laboratory in Peshawar. This laboratory also trains trainers and supervisors. The basic training in malaria microscopy takes 1 month.

For work in Afghanistan, pupils are recruited from inside Afghanistan through the health care units there. After training, the laboratory workers are provided with a microscope and expendable supplies to last for some months. They are attached to health care units sponsored by various NGO's. The first batch of microscopists (22) started work in Afghanistan early this year. Therefore, the quality control (obviously very difficult to operate anvway) and return of results is only just starting to function (Annex 4 ). New courses lasting 4 months will start in December and in Spring 1991.

Refresher courses are planned now, primarily for laboratory workers, in Afghanistan not trained by IMC/MSF in Peshawar. MSF. Belgium is planning to recruit a laboratory technician to travel around Afghaniștan as supervisor. 


\section{CONCLUSIONS}

The malaria situation in the Afghan Refugee camps in Pakistan

Malaria is an important public health problem in several of the AR camps. Despite surveillance, focal spraying and good primary level treatment facilities, this disease figures high among the most frequent diagnoses of hospitalized patients, although with considerable variation from place to place. The situation seems to be worse in South Waziristan, an extremely poor and remote area, than for instance in Mardan.

Although some cases are likely to have been imported from Afghanistan or other places in Pakistan there is sufficient evidence for predominantly local transmission: (a) all age groups of both sexes are equally affected while, usually, only adult men travel to other areas: (b) Vectors are abundant.

Control must therefore aim at reduction of local transmission. Because of the variety in ecological conditions in the various AR camps, the most appropriate control measures may vary with the locality. In some dry areas larval control might be practical, while elsewhere, wall spraying or impregnated nets might be more appropriate.

Insecticide spraying of walls in houses and cattle sheds

Although in some areas resistance of $A$. stephensi to malathion has been confirmed, it appears that the data cannot be extrapolated to all localities in NWFP. It should also be taken into account that some degree of resistance does not always lead to operational failure of control by wall spraying.

The continued increase in malaria rates after spraying with malathion or fenitrothion in, for example, Darsamand (Kohat) and Yakka Ghund suggests that spraying was ineffective. A lower spray coverage than reported, which is indeed suggested by our observations, might (partially) explain the lack of impact on malaria transmission. Another possible explanation might be the AR's habit of frequently replastering the houses and sometimes dusting the walls to remove the dirtv-looking insecticide. Bioassays at regular (weekly or two weekly) intervals would allow assessment of the residual effectiveness of the insecticide on the mud-plastered walls. The mud plaster seems to provide a very poor substrate for adherance of the insecticide: the soil particles quickly come off from the wall when touched. The plaster in houses in the Punjab appears to be of a far more stable structure and it therefore provides a better sprayable surface.

It is clear that if fenitrothion is to be used as an alternative insecticide, more attention will have to be paid to the safety of the spraymen. 
Most refugees have built houses since their arrival in Pakistan but tents provided by the UNHCR are still used by some groups of semi nomadic Afghans who live in camps in the Punjab in the winter months and migrate to Waziristan during the summer months. These people seem to suffer considerably from malaria and spraving of their tents might be an appropriate control method.

To save insecticide and labour, it is recommended to spray only the inner surface of the inner tent according to standard procedures for wall spraving. For reasons of safety to the inhabitants, it is recommended to spray with permethrin (e.g. at a dosage of $0.5 \mathrm{~g} / \mathrm{m} 2{ }^{*}$ ).

Bioassays with the sprayed material should be conducted to evaluate the duration of the residual effectiveness. If this appears to be a few months. only a second sprayround might be needed. Alternatively, it could be considered to experiment with alternative insecticides (e.g. deltamethrin. lambdacvhalothrin), formulations. dosages and application methods to establish an insecticide treatment for tents which lasts sufficiently long to provide protection for the whole transmission season.

\section{Insecticide treated mosquito nets}

Most campsites are located in areas which become very hot in summer and everybody seems to sleep outdoors, in the courtyard or on the roof, during at least 6 months of the year. Transmission of malaria therefore generally must take place outdoors and there is little doubt that treated nets, if used properly, would be effective in reducing transmission. Since the vector mosquitoes are all highly zoophilic, the mosquitoes which are not killed but repelled by the treated nets are likely to be diverted to animals, if available.

Although many of the refugees seem to know mosquito nets, their acceptability for daily use seems to be the main problem. If mosquito nets are to be promoted, the following questions need to be addressed:

- which netting material, mesh size and colour are preferred;

- what are the most practical support systems for the nets when they are used outdoors (with and without a bed);

- how long would the preferred type of net last when used daily;

- how long would an insecticide application remain effective in a daily used net;

- would washing or exposure to sunlight of the nets be a problem;

samples of tenting material have been sent to Dr C. E. Schreck, USDA, Gainesville, Florida, for advice on the most appropriate treatment 
what is the

to promote the use of the nets (the mullah(?):

- what is theuld people accept to pay for the nets:

- how would the nets have to be livery of nets and insecticide. community activity).

A study on the effectiveness and acceptability of treated nets should precede a control programme based on this method. However, it should be realized that due to ecological and possibly, cultural and of a studv in only one village should be interpreted with caution.

\section{Insecticide treated curtains}

Only a few studies showed an entomological or epidemiological impact ho treated strips of netting ("curtains") in the eaves openings of small $(11,12)$. In these studies, hungry mosquitoes tried to enter treated strips of netting a the eaves openings to feed on humans. The human. This model does not as a toxic barrier between mosquito and villages where people sleep outdo to the situation in the refugee cattlesheds because thev need a sate Mosquitoes enter houses and insecticide treated curtains in hafe place to rest. The presence of alternative resting places such as aus mavert mosquitoes to screen. In addition, the inhabitants of sheds. which are difficult to the curtains away from the door an of the houses would have to move prevent degradation of the insecticide window openings every morning to they would have to reverse the procede by the sunlight. In the evenings indoors during most of the transmission . Since people do not sleep the curtains as a direct self-protection season, they would not consider method is therefore dubious.

In the curtain trial in Wana, not only door and window curtains were sprayed but also, with the permission of the houseowners, other room. Like residual which were hanging against the walls in the living providing a toxic resting playing this could kill mosquitoes by longer residual effectiveness of the insecticide in fage is the much permanently attached to the walls. Because the in fabrics which are proportion of available resting areas, the chancenly cover a small settles on it seems small. However, the chance that a mosquito be positively attracted to dark rebrics fome mosquito species are known to be the case here. An experim fabrics for resting and this could also evidence about the effectivental hut type of study should provide more trials are carried out. 


\section{Conclusions regarding Kunar Province}

The Province corresponds exactly to the classical picture of malariogenic river vallevs in Afghanistan. Up to around 1980 . malaria was controlled by regular intradomiciliary spraving. These operations were terminated between 1980 and 1988. Malaria transmission is now sharply seasonal and affects most of the population. The available data do not allow a determination of the relative importance of $P$. $f$. and $P . v$., but the former exists. Considering the finding of more than $50 \%$ of chloroquine-resistance in NWFP, this must be assumed to be a problem here, also.

We have no data to assess the incidence of severe disease or death from malaria. Considering that the CFR from "cerebral malaria" was below $10 \%$ in the best clinical unit we visited (which is unrealistically low for rigorously defined cerebral malaria), it is likely that there is a good deal of hidden mortality. People may prefer to die at home or attempt to travel to Pakistan rather than go to health care units they consider rudimentary, in cases of severe disease.

Despite the absence of local guidelines on malaria treatment. the ideas of health personnel are generally rational. It is encouraging that reserve drugs are so generally available through the private sector. and that health workers have a good understanding of their indication. One should of course not be mislead into thinking that practices are as rational as is said by health workers themselves. There is definitely an unnecessary and dangerous overuse of both chloroquine injections and probably also of reserve antimalarials.

The low population density coupled with the presumed abundance and diversity of breeding sites in the season make it doubtful whether any kind of larval control would be rational at this stage. Vector control would have to be based on attack on adult mosquitoes.

The present-day epidemiology of malaria in Afghanistan

Although the documentation is scanty, it is clear that in many areas of the country there is now a resurgence of both vixax and falciparum malaria. The incidence might further increase in case of a massive influx of returnees from Pakistan, and even more so, if the refugees come from Iran, where they have probably lost any immunity.

The widespread availability and use of chloroquine will probably ensure against epidemics with a high mortality. However, chloroquine-resistant $P . f$. is now prevalent, and one can imagine a scenario combining factors such as: prolonged rains and high temperatures, influx of relatively non-immune returnees, especially children and spread of chloroquine-resistant $P$.f. Under such 
$-28-$

circumstances. spread of $P$. $f$. would be unchecked. The incidence of infections that could not be clinically cured by chloroquine could become high. and one would have a devastating epidemic.

\section{Vector control}

Regarding the possibilities for vector control. the number of options is limited. It would be unrealistic to assume that larval control could play an important role in malaria control in rural systematic control by intradomiction for extremely costly exercise. It mould be an the necessary reconnaissance studies and supervision. In additions, insecticide susceptibility insecticides and equipment or resold in Pakistan. capacity for rapid intervention, it would be desirable to establish a epidemics. However, consider by ULV and intradomiciliary spraying for the epidemiological surveillang the weakness or rather non-existence of the pressure from the population the sharp seasonality of malaria and moment, a system for rapid interven spraying. it appears that at the effects.

The only option left that could possibly lead to a reduction in transmission would be the introduction of insecticide-impregnated bednets or related techniques. Considering the good results obtained in effect, with intradomiciliary spraying, which continued to have some be cautiously optimistic about vectors were partly exophilic, one may if rigorously applied. it is uncertain whether outside in the warm seas could become popular. The habit of sleeping certain areas of Afghanistan bedneusly a serious obstacle. However, in being attached to poles that are driven intoportedly used on roof tops the roots.

The operational obstacles to intradomiciliary spraying programmes mentioned would apply to some extent also to a programme aiming at transmission reduction through the generalized use of impregnated nets. that their use for gnated nets could become popular, it is conceivable Thus, in the initial phase a metion could gradually become widespread. families; if widely adapted, mis could be offered to motivated transmission reduction in the use could at a later stage lead to to document the efficacy, assess the acce. Clearly, it would be necessary operational problems, before imp the acceptability and examine the a policy.

The existence of a capacity for intradomiciliary spraying operations in Kabul and the popular demand for this kind of intervention imply tha once peace is established. it will be difficult to avoid the recommencement of widespread spraying cycles. With the presently and expensive insecticides. Clearly, it is towards more and more toxic impregnated nets should replace wall-spraying to decide whether have a chance in Afghanistan, they sh-spraving. However, if they are to the traditional vector control they should be introduced at a time when 
1. Strengthening the laboratory network

2. Strengthening surveillance

3. Enactment of a drug policy

4. Operational research on vector control (insecticide impregnation techniques) and use of drugs for treatment and prophylaxis

5. Establishment of a malaria action programme based at WHO FO.

\section{Re 1. Strengthening the laboratory network}

The work started by MSF Holland/Belgium based at the Malaria Referral Laboratory (should be reference laboratory!) in Peshawar should continue. The main elements are:

- Training of microscopists

- Quality control

- Refresher courses

Efforts are underway to add direct supervision in Afghanistan. In the future, it may be necessary to pay increased attention to logistics and to decide whether a vertical system for securing laboratory supplies will be more rational than relying on the individual sponsors. These activities should now be coordinated with other efforts in the field of malaria (see following recommendations).

\section{Re 2. Strengthening surveillance}

The system of PCD based on laboratory reports is only starting to work. One could suggest some simplifications; it is for instance unnecessary to monitor the sex distribution of malaria cases (which is included in the routine "greenbook" reporting system for all conditions). However, the managers of this system may find it more practical to continue working with the established form, avoiding the disturbance of petty improvements.

What is now needed is to start consolidation and analysis of these data together with the greenbook malaria data. The distribution of cases detected should be compared with older data fram Kabul.

Retro-information on malaria should be elaborated and distributed to laboratories and doctors; in some cases, supplementary information may be obtained through cross-sectional surveys; the performance of such surveys may seem slightly premature considering the remoteness of possible preventive action. Nonetheless, they can add considerably to the local practitioners' understanding of malaria epidemiology as well as adding bits to the generally still vague picture. These surveys should therefore be encouraged, when the laboratory personnel is certified; the slides should be sent for checking if possible.

Competent clinicians should be identified who could check on the correctness of the data provided by the laboratories for the PCD system and who could provide additional data on monthly cases of:

- hospitalized malaria

- cerebral malaria (well-defined criteria)

- malaria deaths 
At present. the consequences of this monitoring will be limited. However. these steps will provide experience for designing a more comprehensive information and surveillance system. and will provide some baseline information for decision-making. if. with time. possibilities for implementing a true malaria control programme improve.

Re 3. Enactment of a drug policy

In the presence of more than one parasite species and of drug resistance, the rational use of antimalarial drugs to prevent death and severe disease depends to a large extent on the existence of an extensive laboratory network of good quality oriented primarily towards the needs of clinical care. In addition. the enactment of a drug policy requires:

-definition of guidelines for treatment

-distribution of drugs

-education of health workers

-education of the public

\section{Definition of guidelines for treatment}

Guidelines should be based on a limited number of formulations. Under the prevailing uncontrolled transmission. primaquine has no place neither for the prevention of vivax relapses nor for killing $P$.f. gametocytes. The addition of primaquine to chloroquine as a way of limiting the spread of chloroquine-resistance is not a strategy of proven efficacy, and could theoretically lead to a selective pressure in favour of chloroquine-resistant genotypes.

The existence of chloroquine-resistance makes it necessary to deploy Fansidar tablets and quinine injectable. It is doubtful whether chloroquine injectable is really necessary, but since it will continue to be popular, its use should be guided. Quinine ( + tetracycline) tablets would be the most rational choice for Fansidar-resistant cases., but for the time. these will probably be detected so rarely that they can be treated with quinine injections. Chloroquine syrup is of ten dosed wrongly and is not tolerated better than crushed tablets. Amodiaquine is no longer recommended by WHO. because of the high risk of agranulocytosis associated with repeated intake. and because it is only chloroquine-resistant malaria.

Thus, the following formulations should be used:

(1) Tablets of chloroquine diphosphate or sulphate, $150 \mathrm{mg}$ chloroquine
base per tablet

(2) Vials of chloroquine diphosphate or sulphate injectable, $200 \mathrm{mg}$ chloroquine base per $5 \mathrm{ml}(40 \mathrm{mg} / \mathrm{ml})$

(3) Tablets of sulfadoxine and pyrimethamine, "Fansidar", sulfadoxine $500 \mathrm{mg}+$ pyrimethamine $25 \mathrm{mg}$ per tablet

(4) Vials of quinine dihydrochloride injectable, $600 \mathrm{mg}$ quinine salt per
$2 \mathrm{ml}$.

It should be noted that a scale is an obligatory tool for treatment with antimalarials by the parenteral route. 
-31 -

The treatment schedules and

This annex mav be considered their indications are found in Annex 5 .

writing of guidelines in manuas a kind of draft or base document for the production of posters and charts. This training material as well as Translation into Dari and charts. This task can only be done locally. principal target-group shou Pashtun is of course mandatory. The target group doctors. The doce ML health workers, and the secondary and Royal Society of Trepiocument "Severe and complicated malaria" (WHO in 10 copies together with this Medicine and Hygiene, 1990) is forwarded and should be made available report to WHO Field Office. Peshawar, may be requested from the documentors who are interested. More copies

\section{Distribution of drugs}

Judging from the situation in Kunar Province, there is no lack of the needed antimalarials, even at the most peripheral level. Several un-needed drugs are widespread, and one should realize that this education of at best, only be slowly ameliorated, through the following:

1.- Chloroquine tablets should always be available at all health care facilities. In isolated villages, settlements etc., chloroquine
tablets should be kept by responsible persons to be used as first
aid treatment for any fever case on the basis of differ trement for any fever case on the basis of the poster. It may obtained throug whether this deployment of chloroquine is best promotion and distribution by het system" or through active trust should be put in "communealth workers, also whether more families.

2.- At clinics and pharmacies staffed with ML workers, but without a laboratory, chloroquine tablets should be available. The utility of be widely available at is debatable, but since we know that it will it.

3.- At clinics with a laboratory and with an ML worker/doctor, also

"Fansidar" tablets and quinine injectable should be available.

It is clear that when for instance "Fansidar" is alwavs readily available at a nearby pharmacy, there is no need for it to be stocked at the health care unit. In this situation, the pharmacist should be motivated for not misusing the reserve drug; the best tool for this is
probably to provide him with a set of the treatment guidelines.

It is possible that in some Provinces, "Fansidar" is not readily available. as is the case in Kunar. In a kind of "worst case" scenario, as outlined in Conclusions, it would be necessary to apply "Fansidar" as first line treatment of falciparum infection. Given this risk, it is It is therefor to stock a quantity of "Fansidar" tablets at a central place. stock of 30000 commended that WHO Field Office in Peshawar ace. far below the numlets, enough to treat 10,000 adult cases. This may be epidemic, but would probably that would need the drug in case of an present at health facilities in a given situation. 
Education of health workers -

Although malaria is a major problem. it would probably not be justified to run special malaria courses tor health workers. Malaria, especially diagnosis and treatment should be included in training courses and refresher courses together with other clinical subjects. From one viewpoint. malaria belongs together with Maternity and Child Health target diseases such as diarrhoea and respiratory tract infections. From another viewpoint. malaria should be taught together the necessity of undecause of the importance of laboratory diagnosis and the necessity of understanding drug resistance and side effects.

Education of the general public

this point be:

- recognition of the signs of malaria

- the necessity of early treatment with chloroquine - the non-necessity and danger of chloroquine injections, for patients
who can take tablets

- that early treatment of malaria is particularly important for pregnant women and children

The main vehicle for this information will probably be posters. It is always good to inform on what malaria is. how it is transmitted and the life-cycle of mosquitos by radio or other channels, and no opportunity for this should be lost. However, due to the present lack of options for vector control, not too much emphasis should be placed on this. This may change, if preliminary trials (Annex 6) indicate that impregnated nets are both effective and acceptable.

\section{Operational research}

The following operational research is proposed.

A. Evaluation of the effectiveness of insecticide treated mosquito
nets.

B. Evaluation of the effectiveness of insecticide treated "chadors"

C. Probing of the acceptability of impregnated bednets in Kunar
Province.

D. Assessment of the therapeutic efficacy of chloroquine in falciparum

Outline protocols are found in Annex 6.

\section{Establishment of a malaria action programme at WHO Field Office,
Peshawar}

It is clear that the recommendations formulated here do not constitute a malaria control programme. The measures suggested are the programme, or lead to some years might develop into a malaria control future prove valuable for accumulation of experiences that could in the Malaria and Parasitology in Kabul. 
- 33 -

Any such development will require that anti-malaria activities are coordinated. monitored analyzed and adapted. In other words. central management is warranted. This is particularly important, because so many different organisations are now involved. each of them doing highly qualified work, but with little coordination and with little sense of a unifying policy as regards malaria. thus. e.g.: MSF Holland and MSF Belgium taking care of the laboratory network, MSF Holland doing monitoring clinical data.

It appears that this would be a very suitable responsibility for the WHO FO to take up, because of the ease with which it can liaise with the malariologists in the Eastern Mediterranean Regional Office and at HQ. In addition it may be mentioned that the present WRs in Islamabad and Kabul are both malariologists and that the new leader of the WHO FO has considerable malaria experience in the region.

Assuming this responsibility means investing the necessary manpower. At present. the employment of a specialized malariologist is not indicated. What is needed is to assign $30 \%$ to $50 \%$ of the work-hours of a person with a good understanding of epidemiology and public health. who is able to communicate and stimulate cooperation. Work on malaria could very well be combined with responsibilities for e.g. tuberculosis. leprosy or other communicable diseases.

If such a person can be recruited or assigned. it is strongly recommended that he tries to set up a kind of "malaria board" including all the persons involved in malaria-related work in Afghanistan. This group should be able to undertake a critical appraisal of the present report's recommendations, work them into a programme of action. and submit this programme to continuous evaluation and adaptation. 


\section{ACKNOWLEDGEMENTS}

\section{it -}

The authors are indebted to Drs Tarantola and Lyonel-Richter. REL. and to Drs. Vajera. Shidrawi and Kuznetsov. CTD, for valuable discussions during the preparation of this mission. All the persons and entities met in Pakistan and Afghanistan were extremely cooperative and took considerable time to find information and help us in other ways. The staff of WHO's Field Office in Peshawar spared no efforts towards making our mission succeed, and the ability to obtain necessary clearances, transport and translaters with short notice and concurrently with numerous other pressing tasks was most impressive. Dr Menno Bouma. was an inspiring collaborator during all our work in Pakistan. and we can only hope that MSF will be able to find an equally qualified and motivated person to continue his work. The final version of this report has benetited from critical suggestions by Dr Aafje Rietveld, MAL.

\section{REFERENCES}

(1a) National Institute of Medical Research and Training. Annual Report January 1. 1988-December. 31 1988. Lahore. 1989

(1b) National Institute of medical Research and Training. Annual Report January 1, 1989-December 31. 1989. Lahore. 1990.

(2) Zulueta. J.de. Evaluation of the Malaria Control Programme for Afghan Refugees in Pakistan (12 February-11 March 1989). UNHCR. 1989

(3) Zulueta. J.de. Malaria among Afghan Refugees in Pakistan. Report of an evaluation mission (4 October-25November, 1989). UNHCR, 1989.

(4) Suleman, M. Malaria in Afghan Refugees in Pakistan. Transactions of the Royal Society of Tropical Medicine and Hygiene, 82, 44-47, 1988.

(5) Afghan Refugee Health Programme (Chief Commissionerate Afghan Refugees). UNHCR, Islamabad. 1990.

(6) Dhir. S.L. \& Rahim. A. Malaria and its control in Afghanistan (1950-1954). All Institute of Hygiene and Public Health, Calcutta. 1957.

(7) WHO. Base document on Afghanistan 7/71. Annex I. WHO, 1971.

(8) Djelantik, A.A.M. Assignment report. Malaria Control Programme in the Democratic Republic of Afghanistan 15 April - 31 Julv 1975. EM/MAL/169, EM/AFG/MPD/001/RB-DP. WHO, 1979.

(9) Kovchasov, G. Assignment Report 3.Oct. 1979-25.Oct. 1985. Kabul, 1985.

(10) Delfini. L.F. Report on a mission to Afghanistan. Institute of Malaria and Parasitology, Kabul, ll June - \& July, 1987.

(11) Majori, G., Sabatinelli, G. and Coluzzi, M. Efficacy of permethrin impregnated curtains for malaria vector control. Medical and Veterinary Entomology 1, 185 (1987).

(12) Lines, J.D., Myamba, J. and Curtis. C.F. Expeimental hut trials of permethrin-impregnated mosquito nets and eave curtains against malaria vectors in Tanzania. Medical and Veterinary Entomology 1: 37-51. (1987). 


\section{ANNEX 1}

Data from AR camps, NWFP, Pakistan

A. Comparison of parasite rates (P.R.) in Afghan refugee and Pakistani school-children living in same areas in NWF P. Percent positive in each group, which included approx. 200-500 persons. (Courtesy, M. Bouma)

$\begin{array}{ccc}\text { Arca } & 1989 & 1990 \\ & \text { Population } & \text { March/Apr. OctoberMarch/Apr. }\end{array}$

Kohat

$\begin{array}{llll}\text { A.R. } & 17.8 & 10.8 & 11.6 \\ \text { Pakistani } & 12.8 & 14.5 & 3.9\end{array}$

Yakka Ghund A.R.

Pakistani

8.8

11.9

2.2

3.4

4.3

5.1

B. Kohat District Hangu area

Courtesy, PDH ano IRC

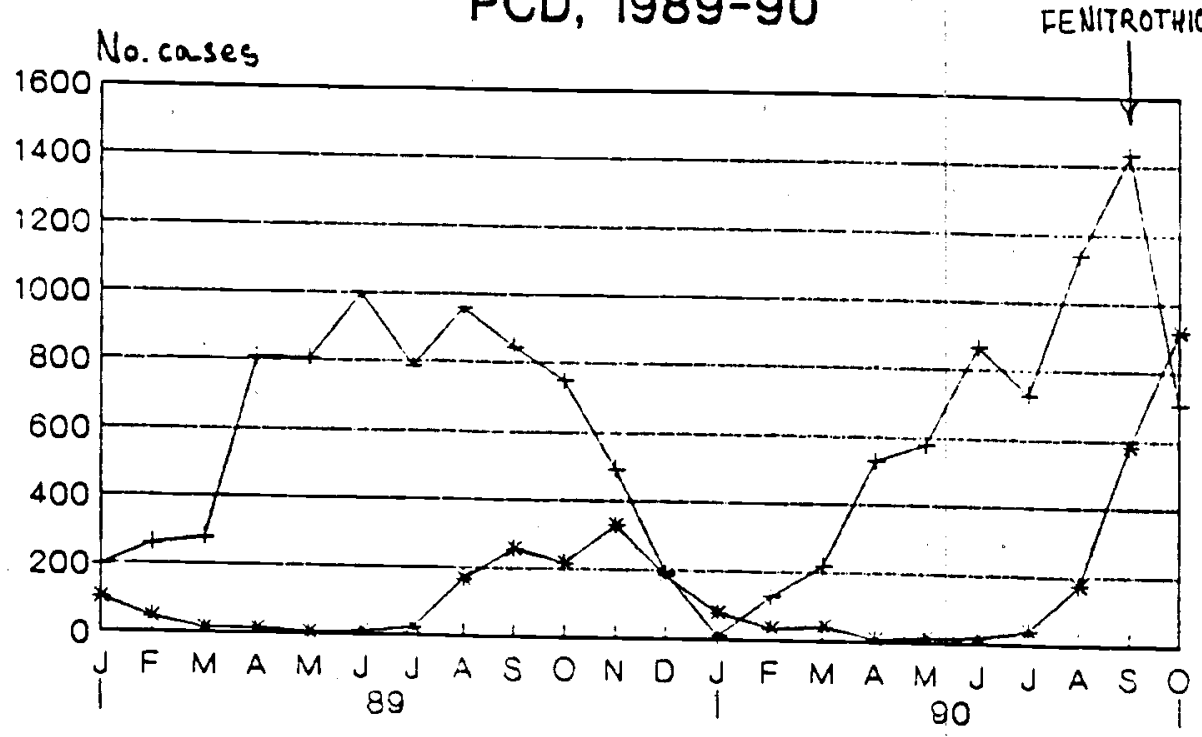

C. Yakka Ghund Camp, Mohmand Agency

PCD, $1989-90$

PCD, $1989-90$

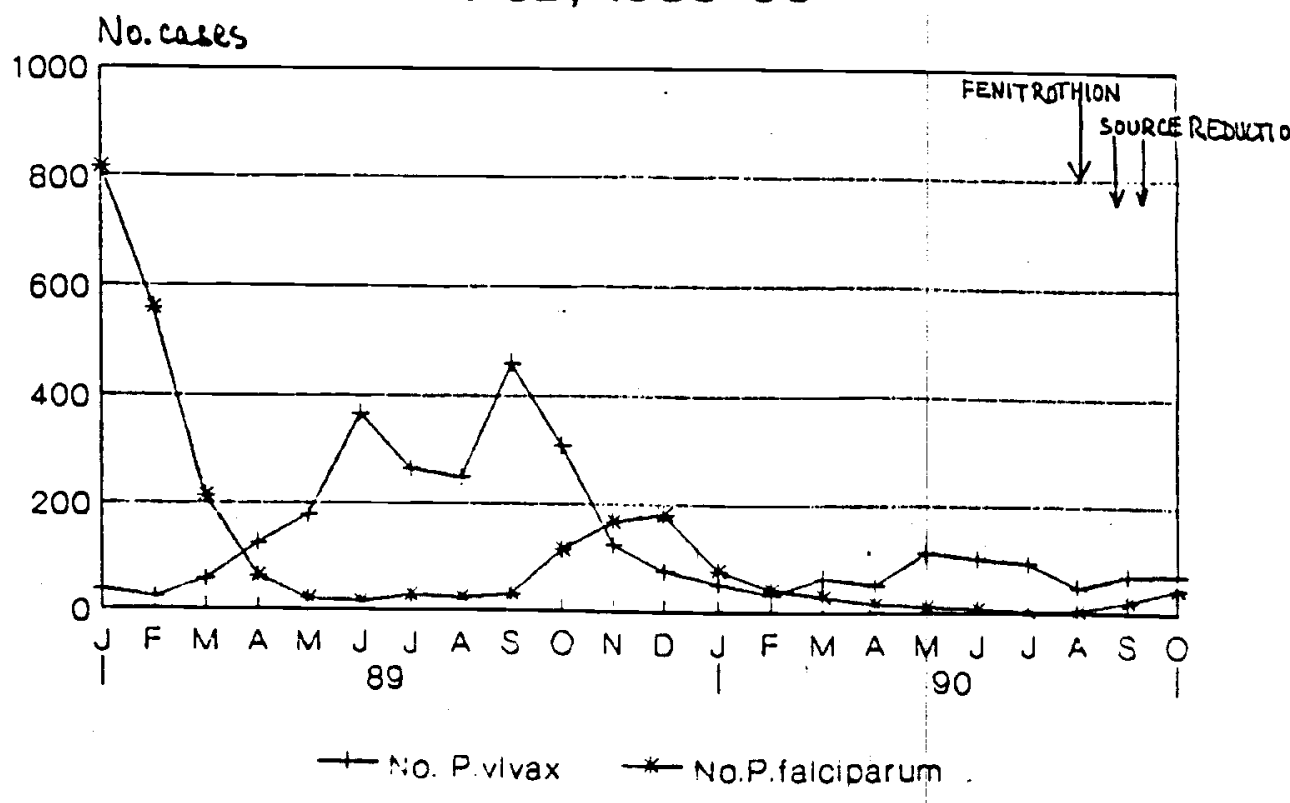


ANNEX 1, p. 2

D. Mardan District

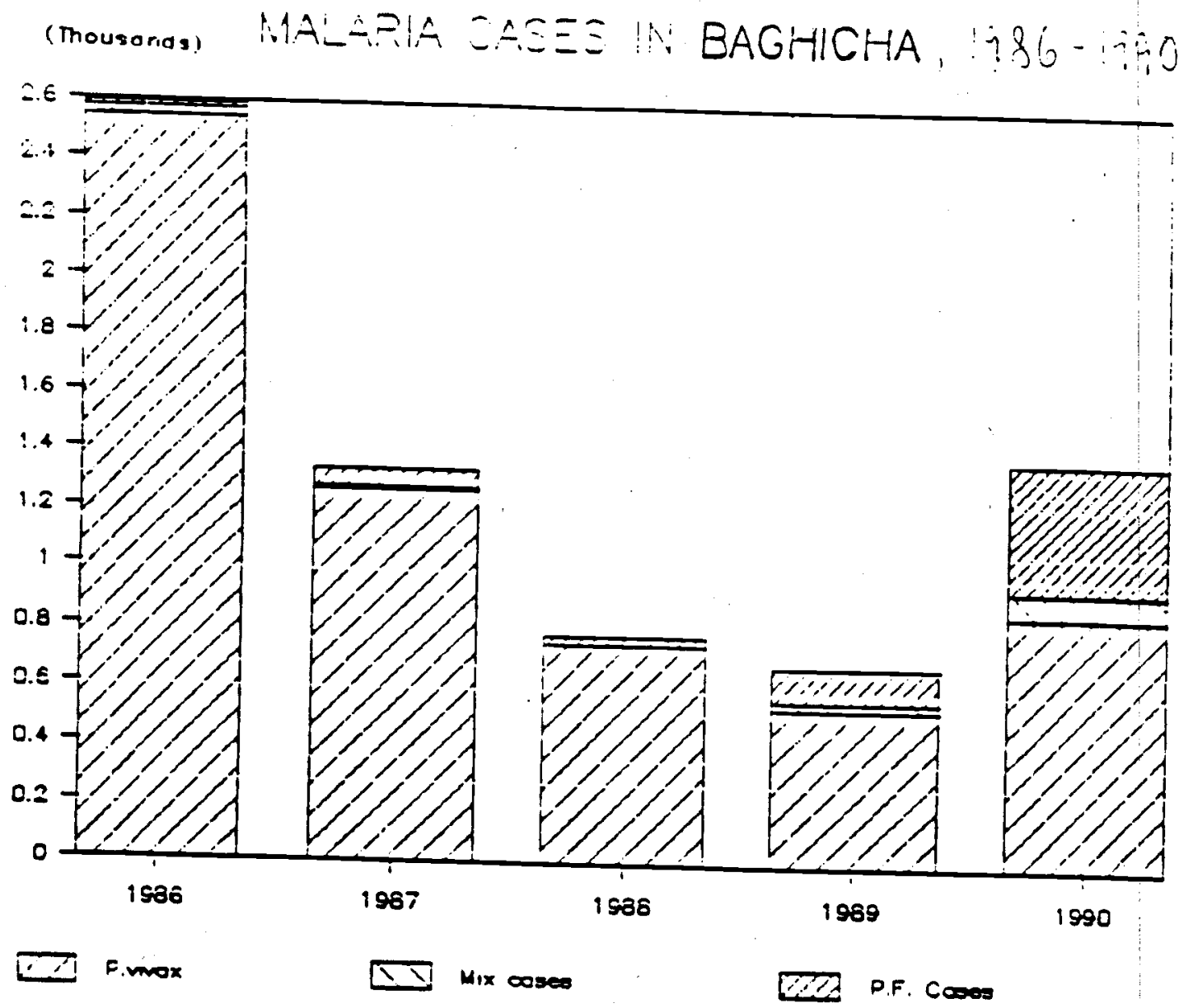

Bhaghicha PCD, 1990

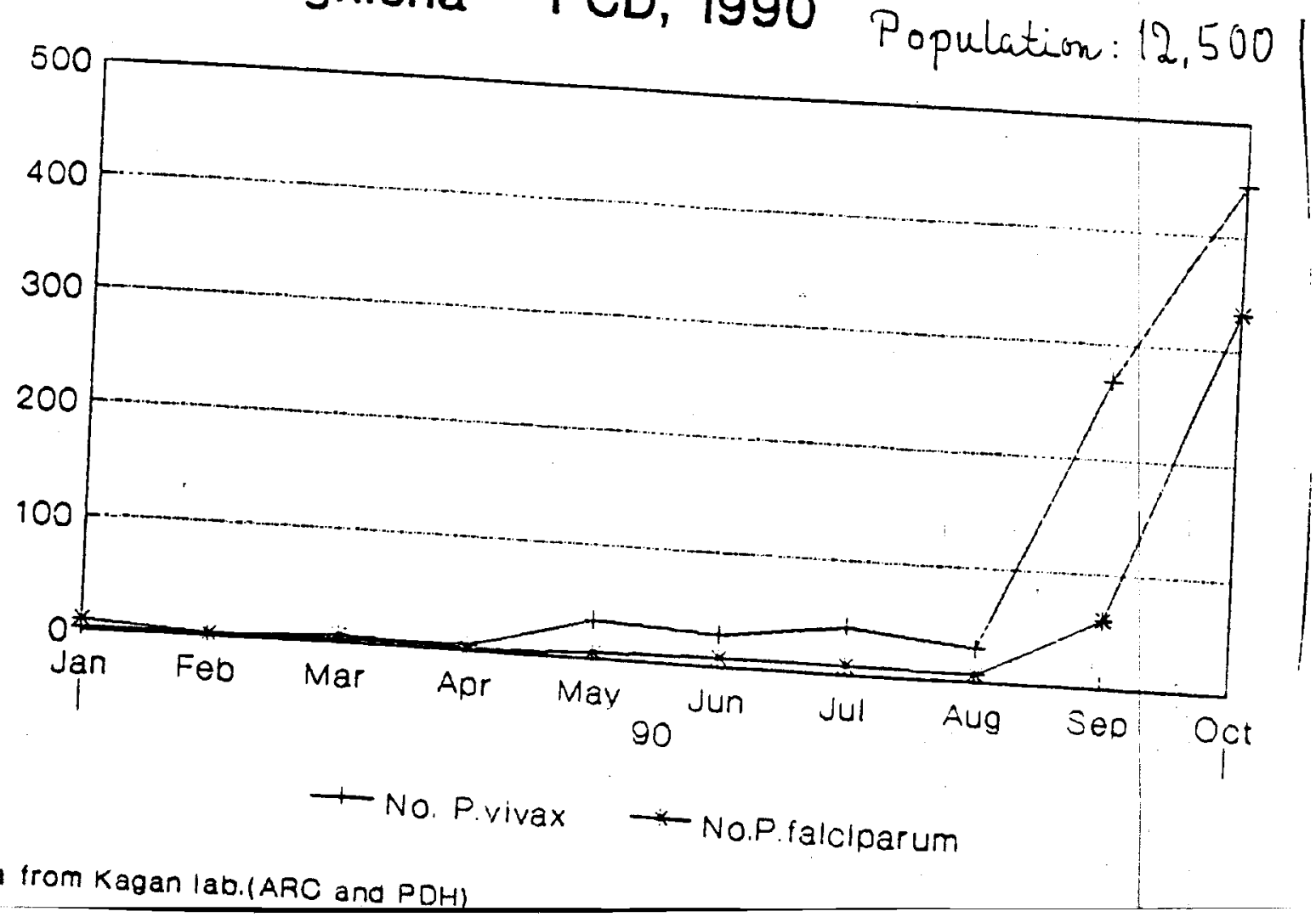


PARASITOLOGICAL DATA BY UNITS - 1987- $-x)$

\begin{tabular}{|c|c|c|c|c|c|c|c|}
\hline$U N I T$ & $\begin{array}{l}\text { POPULATIO:i } \\
\text { AT } \\
\text { PISK } \\
\end{array}$ & $\begin{array}{c}\text { SIIDES } \\
\text { COILECT }\end{array}$ & POSIT. & S.P.R. & A.P.I" & A.B. $\ddot{E}_{\bullet} \dot{R}_{.}$ & F. $\ddot{F} \cdot \bullet$ \\
\hline KUNDUZ & 245309 & 15138 & 4002 & 2.6 .4 & 16.3 & 6.2 & - \\
\hline PUIIKEOMRI & 232968 & 14867 & 2668 & 18.0 & 11.5 & 6.4 & - \\
\hline EAG KILAN & 173636 & 21609 & 8213 & 38.0 & 47.3 & 12.4 & - \\
\hline KHANABAD & 139841 & 7236 & 4383 & 56.7 & 31.3 & 5.5 & - \\
\hline KMOJIGKAR & 208156 & $10 \quad 544$ & 3726 & 35.3 & 17.9 & 5.1 & - \\
\hline IMAMS AHIB & 164217 & 11879 & $\begin{array}{ll}3223 \\
\end{array}$ & 27.1 & 19.6 & 7.2 & - \\
\hline BADEKISEAM & $34056^{\prime}$ & 50326 & 18933 & 37.6 & 55.6 & 14.8 & $i$ \\
\hline KASHAN & 63263 & 4173 & 2249 & 53.9 & 35.5 & 6.6 & - \\
\hline TAIOQUAN & 151719 & 34729 & 16259 & 46.8 & 107.2 & 22.9 & - \\
\hline $\begin{array}{l}\text { N. E. REGION } \\
T 0 T A L\end{array}$ & 1719667 & 171001 & 63656 & 37.2 & 37.0 & 9.9 & - \\
\hline MAZARISHARIR & 389506 & 26978 & 1457 & 8.6 & 3.7 & 4.4 & - \\
\hline JOSJAN & 479496 & 9324 & 1514 & 16.2 & 3.2 & 1.9 & 3 \\
\hline FARIAB & 326715 & 26567 & 3680 & 13.9 & 11.3 & 8.1 & - \\
\hline $\begin{array}{l}\text { N. H. RES ION } \\
m=m: I\end{array}$ & 1195717 & 52869 & $\begin{array}{ll}6 & 651\end{array}$ & 12.6 & 5.6 & 4.4 & 3 \\
\hline KABUL - & 1.333666 & 151838 & 54509 & 35.9 & 40.9 & 21.4 & 761 \\
\hline PARWAN & 367586 & 11695 & 1188 & 10.2 & 3.2 & 3.2 & 50 \\
\hline KAPISA & 260115 & 4395 & 100 & 2.3 & 0.4 & 1.7 & 101 \\
\hline$T 0 T A L$ & 1961367 & 167928 & $\begin{array}{lll}55 & 797\end{array}$ & 33.2 & 28.5 & 8.9 & 912 \\
\hline EERAT & 389840 & 31819 & 435 & 1.4 & 1.2 & 8.2 & 1 \\
\hline BADGHIS & 171300 & 7195 & 2153 & 29.9 & 12.6 & 4.2 & - \\
\hline SHENDAR & 65460 & 12460 & 1048 & 8.4 & 16.0 & 19.0 & - \\
\hline $\begin{array}{l}\text { W: REGION } \\
\text { TOT A L }\end{array}$ & 626600 & 51474 & 3636 & 7.1 & 5.8 & 8.2 & 1 \\
\hline $\begin{array}{l}\because S_{\bullet} P_{\bullet} R_{0}= \\
\cdots A \cdot F \cdot I_{0}= \\
\because A B E R= \\
\because A \text { P.I. }=\end{array}$ & $\begin{array}{l}\text { de Positivit } \\
\text { dal Parasite } \\
\text { ual Blood Ex } \\
\text { smodium falc }\end{array}$ & $\begin{array}{l}\text { Rate por } \\
\text { Incidence } \\
\text { acination }\end{array}$ & $\begin{array}{l}\text { nt } \\
\text { o thou } \\
\text { o fer }\end{array}$ & nd & & & \\
\hline
\end{tabular}


ANNEX 1., p.3

D. ( cont.)

MALARIA CAEEミ IN KAGAN, $1987-I J$

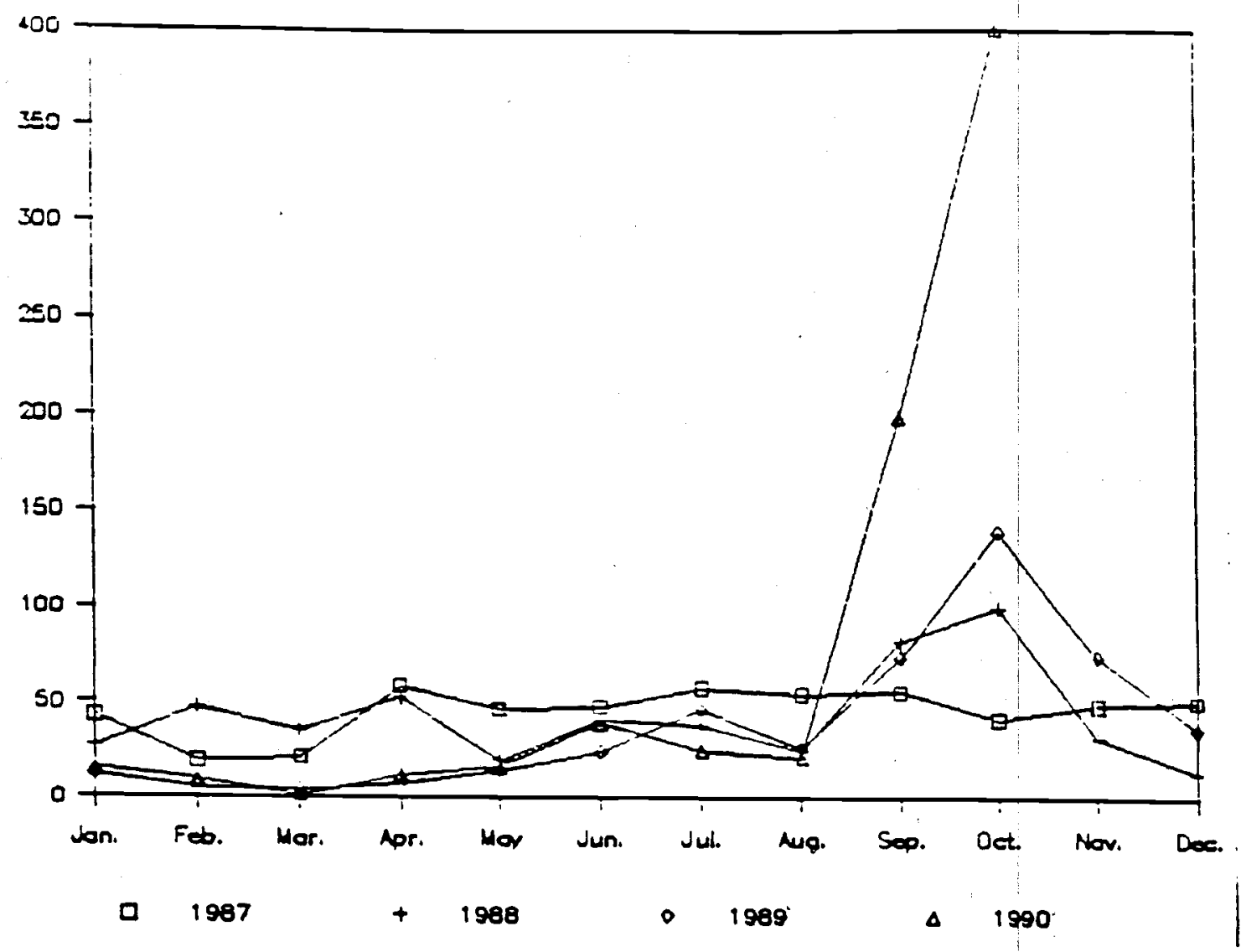

Kagan PCD, 1990

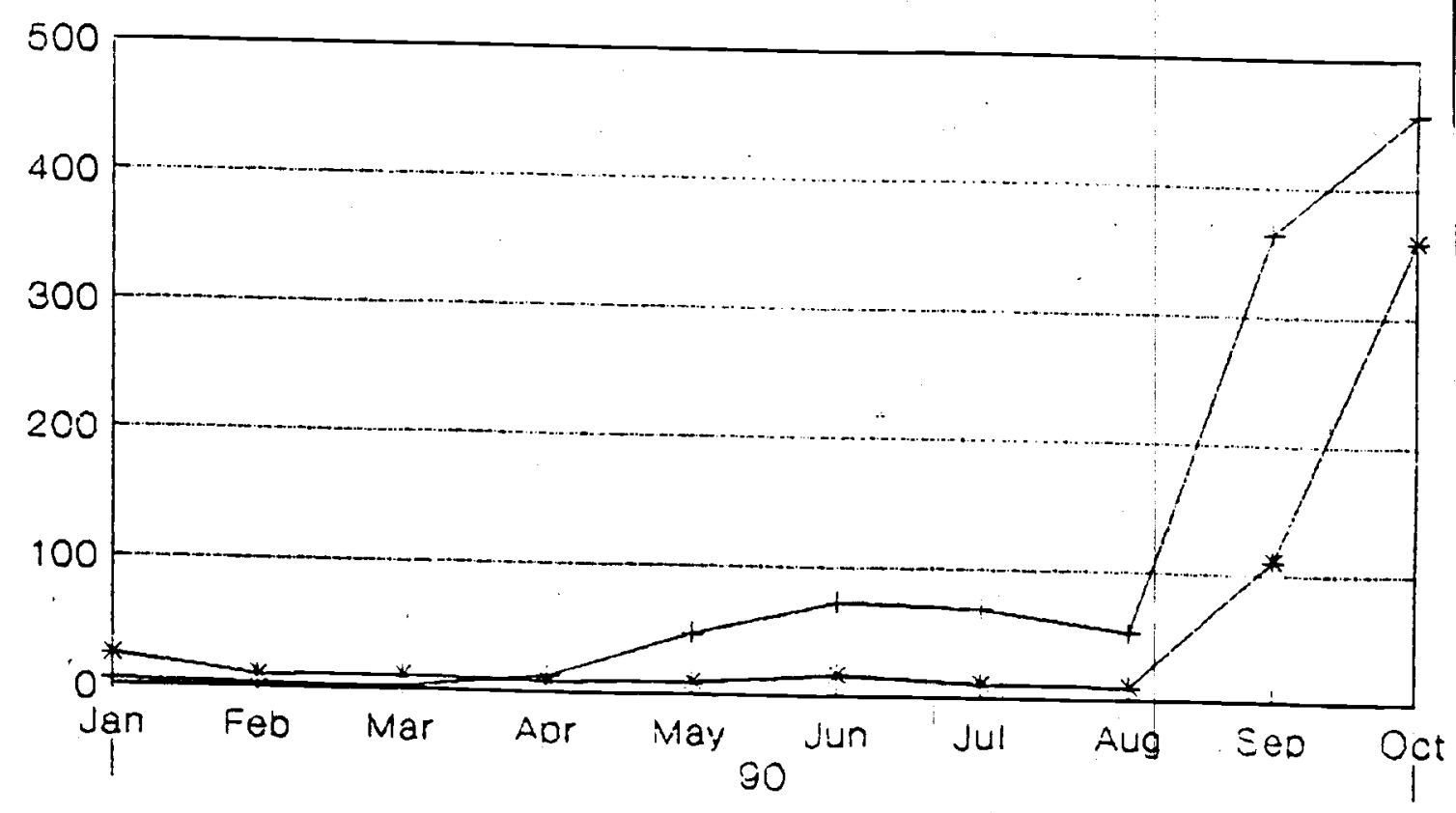

+No. P.vivax \# No.P.ialcloarum 
$\Lambda$ NNEY. 2, p.2

FARASITOLOGICAL DATA BY UIITS - 1987 -

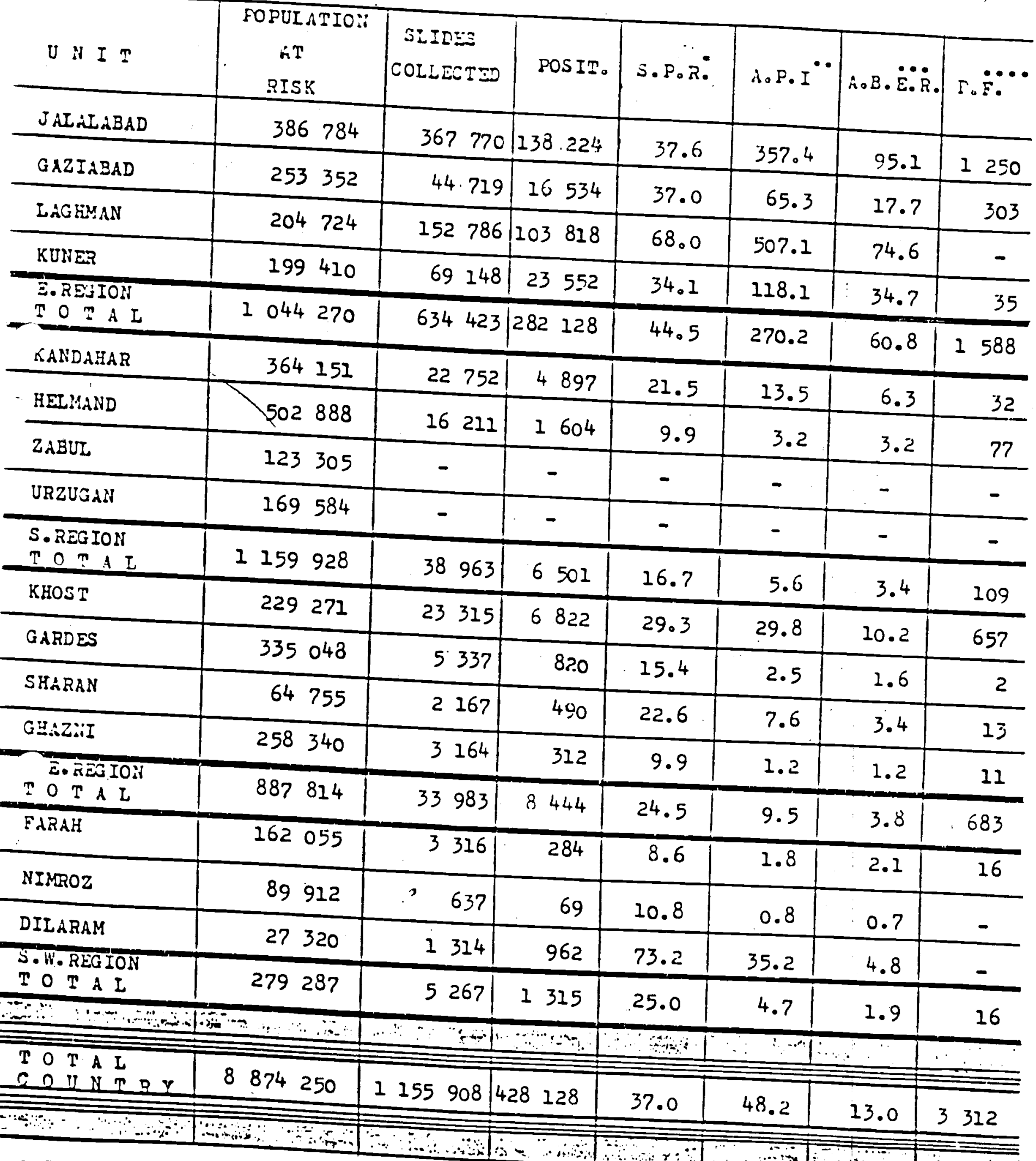

- S.P.R. = Slide Positivity Rate ger cent

- A.E.I. = Annual. Parasj.te Incidence pcr thousand

-. ABER = annual blood Exagination fiśe for cent

-... H. . = Plascodium falcinerum 


\section{ANNEX 3}

"Greenbook" data for January-October 1990, derived from

54 observation posts in Afghanistan (Source:IMC. Peshawar)

Patient population:

$\begin{array}{lcll} & \text { Adults } & \text { Children } & \text { Total } \\ \text { Male } & 20,958 & 2924 & 23,886 \\ \text { Female } & 8,918 & 2019 & 10,937(31 \%)\end{array}$

Total $30,285 \quad 5,115(15 \%) \quad 34,823$

Unfortunately, the definition of children is not clear. If "children" means patients under 5 years of age. then $15 \%$ corresponds to approx. the patients.

Prevalence of selected conditions

Percentage of cases in all observation posts

Malaria

Acutc URTI

Pneumonia

Acdiarrhoca

Fever

\begin{abstract}
Adults
\end{abstract}
3.6

4.2

1.6

1.1

0.6
Children

2.7

4.0

9.9

11.0

1.4
Total

3.5

5.3

2.9

2.5

0.8
Max \% in any obs post (all patients)

11.7

10.7

5.4

4.1

4.4

In adults, altogether, malaria ranks as the fifth most frequent category, after Gastritis, heartburn. indigestion; Acute bronchitis:
Intestinal parasites; and Acute URTI. In children, malaria ranks as no. 14, after Acute diarrhoea: Pneumonoa:
Otitis: bronchitis: Intestinal parasites: Giardia; Acute URTI: Bacillary
dysentery; Amebic dysentery Pertussis. 


\section{ANNEX 4}

\section{MALARIA LABORATORY ACTIVITIES IN AFGHANISTAN}

4.a. Placement of microscopists in Pakistan according to data
from Peshawar

\begin{tabular}{lll} 
Rcgion & Province & No \\
East Ccntral & Kapisa & 4 \\
& Parwan & 4 \\
& Wardak & 15 \\
\hline & Logar & 6 \\
& Bamyan & 0 \\
Ghazni & 9 \\
Eastern & Paktya & 8 \\
& Nangarhar & 8 \\
North-Eastern & Laghman & 2 \\
& Kunar & 10 \\
& Badakhshan & 3 \\
& Takhar & 0 \\
Northcrn & Baghian & 3 \\
& Kunduz & 0 \\
& Samanghan & 1 \\
& Balkh & 1 \\
& Jawzan & 1 \\
North-Wcstcrn & Fargab & 2 \\
& Badghis & 1 \\
& Herath & 3 \\
& Farah & 1 \\
& Ghor & 1 \\
& Nimroz & 0 \\
& Helmand & 0 \\
& Qandahar & 2 \\
& Zabul & 0 \\
& Oruzgan & 0 \\
& Paktika & 4
\end{tabular}

\section{4.b. Laboratory Reports (IMC)}

Only one observation post has started sending monthly reports:

Clinic in Khidri village, Sorkh-e-Parsa District, Parwan Provincc, Central
Region

\begin{tabular}{lcclll} 
Month & \multicolumn{2}{c}{ Slides examined Positive (\%) } & P.v. & P.f. & Mixed \\
August & 418 & $90(22)$ & 62 & 23 & 5 \\
September & 480 & $96(20)$ & 81 & 14 & 1 \\
October & 417 & $11(2.6)$ & 6 & 4 & 1
\end{tabular}

These results are the only "hard data" on malaria from inside Afghanistan. most malarious in the country (1986 SPR that in 1986, no P.f. infections were detected. 


\section{GUIDELINES FOR THE TREATMENT OF MALARIA IN AFGHANISTAN}

\section{First-line treatment}

Is applied to cases of uncomplicated malaria diagnosed with or without the support of the laboratory, whether vivax or falciparum. The treatment normally consists of chloroquine tablets $(150 \mathrm{mg}$ chloroquine base per tablet) in the following dosage.

$\begin{array}{llll}\text { Age } & 1 \text { st day } & \text { 2nd day } & 3 \text { rd day } \\ 0-1 \text { months } & 1 / 4 & 1 / 4 & 1 / 4 \\ 2-3 \text { months } & 1 / 2 & 1 / 4 & 1 / 4 \\ \text { 4-11 months } & 1 / 2 & 1 / 2 & 1 / 2 \\ \text { 1-3 years } & 1 & 1 & 1 / 2 \\ 4-6 \text { years } & 11 / 2 & 11 / 2 & 3 / 4 \\ 7-11 \text { years } & 21 / 2 & 21 / 2 & 1 \\ \text { 12 years and over } & 4 & 4 & 2\end{array}$

This information should be presented as an attractive poster with WHO written on it, showing the tablets so that the health worker can use it to present dosages. The poster should also transmit the following messages:

"- All cases of malaria should be treated with chloroquine tablets, including those in babies and pregnant women. Young children should be treated with crushed tablets in water.

- Chloroquine injections can be dangerous. Young children, when very sick, can die from them. They should be given only when absolutely necessary and only by qualified health workers."

The above treatment schedule should also be included in a manual starting with an explanation of the symptoms of malaria. Further, The manual should include the following treatment schedules:

Treatment with chloroquine injections

Chloroquine may be given by the intramuscular route. It should not be given intravenously, not even as infusion. Injections should be given only when absolutely necessary, that is when the patient is too ill to take tablets. The dosage should be chloroquine base $2.5 \mathrm{mg} / \mathrm{kg}$, repeated every 4 hours. For children, correct dosage is only possible, if the child is weighed. The formulation most commonly used in Afghanistan contains chloroquine base $200 \mathrm{mg}$ per $5 \mathrm{ml}(40 \mathrm{mg} / \mathrm{ml})$. With this formulation, the volumes to be injected 4 -hourly are as follows (with different formulations, the volumes will

$\begin{array}{lll}\text { Weight }(\mathbf{k g}) & \text { Dosage }(\mathbf{m g}) & \text { Dosage }(\mathbf{m l}) \\ 3-5 & 7.5-12.5 & 0.2-0.3 \\ 5-8 & 12.5-20 & 0.3-0.5 \\ 8-12 & 20-30 & 0.5-0.75 \\ 12-16 & 30-40 & 0.75-1 \\ 16-24 & 40-60 & 1-1.5 \\ 24-32 & 60-80 & 1.5-2 \\ 32-40 & 80-100 & 2-2.5 \\ 40-48 & 100-120 & 2.5-3 \\ 48-60 & 120-150 & 3-5\end{array}$


ANNEX 5, p.2

\section{Second line treatment}

Second-line treatment with "Fansidar" is applied in cases of chloroquine-resistant falciparum malaria. Chloroquine, is always more
effective than "Fansidar" in vivax malaria.

"Fansidar" can have dangerous side-effects. The two most common are Stevens-Johnson"s syndrome and agranulocytosis. Stevens-Johnson"s syndrome is a generalized allergic reaction involving the skin and the blood cells. This patients treated can lead to any kind of severe infection. Sometimes the treatmant "Fansidar" get agranulocytosis a few weeks after causing tever. A that the patien A health worker without access to a laboratory mav think may kill the patient. Therefore.

(a) "Fansidar" should be reserved for cases of malaria resistant to chloroquine. Resistance can only be diagnosed with the help of microscopy (see below).

(b) "Fansidar" must never be given to a patient who has had an allergic reaction to it or to another sulfa drug (e.g.

(c) A treatmexazol, sulfame thizol or sulfadiazine).

A treatment with "Fansidar" must never be repeated within an
interval of 3 weeks

(d) "Fansidar" must not be given to children below the age of 8 weeks. "Fansidar" may be given to pregnant women, as treatment.

How is chloroquine-resistance diagnosed?

(1) Chloroquine-resistance is suspected if a patient treated for malaria with chloroquine over 3 days in symptoms re continues to have symptoms of malaria. or if the chloroquine treatmen a period of 4 weeks from the start of the taken the the full chl. (If it is uncertain whether the patient has have been repeated. if possible, under chloroquine-treatment should be

(2) If chloroquine-resistance is suspected, a slide must be prepared. If the patient is first seen at a health care unit with no laboratory, referral to a place with laboratory is necessary).

(3) Chloroquine-resistance is proven if the slide shows asexual (Plasmodium falciparum)i.e. rings or trophozoites), and at least 7 days have passed since with "Fansidar".

- If only 4 to 6 days have passed since chloroquine treatment was started, then chloroquine-resistance is not proven, but if the

- If the slide is negative or shows. "Fansidar" should be given. not be malaria at all. Examins only gametocytes, the problem may worthwhile to take a slide a fe patient carefully. It may be

- Do not give "Fansidar" without a days later. chloroquine resistance. 
ANNEX 5, p.3

The dosage of "Fansidar".

"Fansidar" is available in tablets containing sulfadoxine $500 \mathrm{mg}$ and pyrimethamine $25 \mathrm{mg}$. The correct dosage is sulfadoxine $25 \mathrm{mg} / \mathrm{kg}$ bodv dosage is as follows: $1.25 \mathrm{mg} / \mathrm{kg}$ body weight. In relation to age, the

$\begin{array}{lll}\text { Age group } & \text { Weight range } & \begin{array}{l}\text { No.tablets } \\ \text { (single dose) }\end{array} \\ \begin{array}{l}\text { 8weeks-1yr. } \\ 1-3 \text { years }\end{array} & 4.0-9.9 \mathrm{~kg} & 1 / 4-1 / 2 \\ 4-6 \text { years } & 10.0-14.4 \mathrm{~kg} & 1 / 2-3 / 4 \\ 7-11 \text { years } & 14.5-18.4 \mathrm{~kg} & 1 \\ 12-15 y c a r s & 18.5-34.9 \mathrm{~kg} & 11 / 2 \\ 16 \text { and more } & 35.0-59.9 \mathrm{~kg} & 2 \\ & 60 \text { and more } & 3\end{array}$

"Fansidar" should not be given to children under the age of 8 weeks. and the same goes for with quinine in case of chloroquine-resistance. given (see above).

\section{Resistance to "Fansidar"}

Resistance to "Fansidar" in falciparum malaria is presumably quite rare in Atghanistan. but cases will appear sooner or later (sooner, if chloroquine-resistance, but Resistance is diagnosed precisely as is treatment should not be repeated difference is that a "Fansidar" Therefore, it is better to make sure within an interval of 3 weeks. correctly in the first instance. - by that the treatment is taken presence of the health worke, - by letting patient take it in the good evidence that the patient or perhaps the pharmacist). If there is malaria. give 7 days of patient has "Fansidar"-resistant falciparum tablets are available. treatment with quinine intramuscular. If quinine intramuscular, is preferable. How these, in the same dosage as that for most health care units it hever. "Fansidar"-resistance is so rare quinine tablets.

Cases of resistance to "Fansidar" should be reported by the should be in the form the WHO Field Office. Peshawar. The report including the probable a letter stating all details of the case, treatments given. It is of cographical origin, laboratory results and accompanied by slides. 
ANNEX 5, p.4

III. The treatment of complicated malaria

Complicated malaria is malaria caused by Plasmodium falciparum accompanied by complications from one or more organ systems.

Cerebral malaria is the most famous form of complicated malaria. In rigorously defined cerebral malaria, the patient is in unrousable coma, but cases in with other cerebral symptoms such as psychosis or convulsions should also be treated as cerebral malaria. On the other hand. febrile convulsions in young children. where the child quickly same goes for the contusion that be considered cerebral malaria, and the of any age.

Other important forms of complicated malaria are malaria with severe anemia, hepatic malaria (may look like hepatitis), and malaria with kidney tailure and hemoglobinuria - "black water fever".

A diagnosis of complicated malaria can only be made with certainty, if a slide shows asexual $P$. falciparum. Usually but not always, the parasites are numerous. If cerebral malaria is suspected, a lumbar puncture should be performed, if possible. for a patient with bacterial meningitis mav have malaria parasites in the blood. Although treatment should preterably be based on a microscopical diagnosis, it should on the other hand not be delayed. if microscopy is not at hand. If a health worker believes a patient suffers from cerebral malaria. he should start treatment at once. Sometimes it may be advisable to give a first dose of quinine, and then transfer the patient to a hospital which is better
equipped.

In all forms of complicated malaria. but especially in cerebral malaria and in malaria in pregnant women, hypoglycemia (too little sugar in the blood) is very common. This is a dangerous condition. Therefore, any unconscious patient with malaria should receive - together with the malaria treatment - an intravenous injection of $50 \%$ glucose or infusions of glucose, best 10 or $20 \%$. If this is not available. try to feed the patient via a nasogastric tube, and if this is not available either. try whether it is possible to feed the patient by mouth. In young children to the lungs.

The best treatment for complicated malaria, now that chloroquine-resistance is appearing, is quinine by the intramuscular route. Many older doctors are used to giving quinine as intravenous infusion, but intramuscular injections of quinine arejust as effective and much safer. If quinine is not at hand, you may use intramuscular chloroquine (see I). If this is not available either, try to make the patient ingest chloroquine or Fansidar tablets. If this is difficult, don't risk aspiration: transfer the patient as quickly as possible. 
ANNEX 5, p.5

The dosage of quinine

The dosage of quinine is $10 \mathrm{mg}$ of quinine salt per $\mathrm{kg}$ body weight every 8 hours. The vials of quinine most commonly used in Afghanistan contain $600 \mathrm{mg}$ quinine in $2 \mathrm{ml}(300 \mathrm{mg} / \mathrm{ml})$. With these. the volumes to be given in relation to weight are as follows. With different vials. the volumes are of course different. Note, that just as with chloroquine. you cannot dose quinine injections correctly without weighing the
patient.

Weight

$4-4.9 \mathrm{~kg}$

$5-7.4 \mathrm{~kg}$

$7.5-9.9 \mathrm{~kg}$

$10-14.9 \mathrm{~kg}$

$15-19.9 \mathrm{~kg}$

20-29.9kg

$30-39.9 \mathrm{~kg}$

40-49.9kg

$50 \mathrm{~kg}$ or more
Quinine $\mathrm{HCl}$ or sulphate perdose Volume perdose

$40-50 \mathrm{mg}$
$50-75 \mathrm{mg}$
$75-100 \mathrm{mg}$
$100-150 \mathrm{mg}$
$150-200 \mathrm{mg}$
$200-300 \mathrm{mg}$
$300-400 \mathrm{mg}$
$400-500 \mathrm{mg}$
$600 \mathrm{mg}$

$0.1-0.2 \mathrm{ml}$
$0.2-0.3 \mathrm{ml}$
$0.3 \mathrm{ml}$
$0.3-0.5 \mathrm{ml}$
$0.5-0.7 \mathrm{ml}$
$0.7-1.0 \mathrm{ml}$
$1.0-1.3 \mathrm{ml}$
$1.3-1.7 \mathrm{ml}$
$2 \mathrm{ml}$

The treatment with intramuscular quinine should continue until the patient is well enough to take oral medicine. When this happens, the patient should normally be given a single dose of Fansidar (see II). If no Fansidar is available. or the patient does not soon improve (consider whether the patient suffers trom a different disease), continue with quinine injections to complete 7 days of treatment. Quinine and chloroquine together may cause dangerous side-effects, so try to avoid treating a patient with both of these drugs. Never treat a patient with quinine and chloroquine injections at the same time.

Quinine is still useful for complicated malaria. For vivax malaria. chloroquine is always better. For uncomplicated falciparum malaria. there is no reason to give quinine. If we use quinine too of ten for falciparum malaria, we shall soon get resistance to quinine as well as to chloroquine. So be careful: use it only when really necessary. The
same applies to Fansidar.

Doctors who want to know more about complicated malaria mav request a booklet "Severe and complicated malaria" from the WHO Field Office in than treated. The occurrence of numerous cases of compe prevented. rather a sign that cases of uncomplicat numerous cases of complicated malaria is treatment at the right time of doctors to find out what is that is: sufficiently early. It is the task to take corrective action.

The essential step mav be either to educate the public on getting treated in time or to make sure that ML workers at clinics follow the blood examined before thev start on an antimalarial treatme their attitude is quite correct if microscopy antimalarial treatment. This is not, treatment may be dangercopy is readily available. But if it 
ANNEX 5, p.6

IV. Slide-control of malaria patients

Many health workers have been educated to take slides after treating especially falciparum malaria patients to see whether the chloroquine was effective. In the conditions of Afghanistan. this is not always the best course. Some patients may have a positive slide after treatment indicating resistance, but if their general health is good. and they have no symptoms of malaria, it may not be wise to expose them to the risk of side-effects from "Fansidar". Theretore,in routine work. health clinical care to the patient: condition to the patient: Have a slide taken. whenever the clinical of the slide might help you take the right decision think the result come for control, if you are worried right decision. Ask the patient to for instance if you are treating a pregnant womdition might get worse. anemic child with chloroquine for falciparum malaria. But don't overburden the laboratory with routine controls of all patients. 


\section{OUTLINE PROTOCOLS FOR OPERATIONAL RESEARCH}

\section{A.Evaluation of the effectiveness of insecticide treated mosquito nets}

\section{Investigators}

It is hoped that MSF will recruit a person with training in entomology as replacement for Dr M. Bouma. With support from PDH field staff and medical officers. from NIMRT and from CTD. this person should be in a good position to carry out this and other investigations inside
Pakistan.

\section{Introduction}

Community wide use of treated mosquito nets would probably result in a reduction of the inoculation rate and. in areas with low to moderate transmission. a reduction in prevalence rates. In areas with a relatively intense transmission. a reduction in morbidity and parasite densities in positive cases is more likely than a reduction in prevalence rates. Persons who do not use mosquito nets, if thev are a minority, are likely to benefit from the use of treated nets by the majority of the community.

Community protection is the desired effect of large scale use of treated nets. Assessing such an effect in a trial would require a number of randomly selected intervention and control villages. A trial of the situation of Afghanistan. community-wide coverage where the machinery necessary for obtaining is proposed, aiming at a cannot be envisaged. Therefore, a simple design treated nets used by individual hous of the protective effect of households with individual household within one community. Because only a small proportion in the same community would serve as a control. should use treated nets. It came total number of households, e.g. $5 \%$, in the "control" households will then be assumed that the malaria risk use of nets in the test group.

\section{Study design}

It is proposed that the trial is carried out in a refugee village with at least 12,000 inhabitants or about 2.000 households. One of the villages in Mardan District. NWFP should be suitable. Transmission of $P$. f alciparum during the last years should have been monitored reliably and should be considerable. All households should be mapped intervention. A similar them should be randomly selected for the test and control house series will be selected as controls. All the willingness to co-operate in will be visited and asked for their number can be consideredas an trial. If needed, the household next in

The households selected for nets will receive information on the correct use of the treated nets: the total number of nets needed for each household will be assessed as well as the need to give help for the of the trial the supports for outdoor use of the nets. At the beginning will be provided free to the "test"

A method will have to be devised which allows some monitoring of the daily use of the nets. without violating the privacy of the users. It is 
ANNEX 6, p.2

Just betore the introduction of the treated nets. at the beginning of thetransmission season in April. blood sampleswill be takentrom all household members in both groups. Micro-hematocrit and spleens will be checked in children 2.9 years old. This will be repeated at the end of the trial period in November. During the trial period. the inhabitants of the village should go to the Basic Health Linit in the village in the even of any disease episode. If malaria is suspected (complaints of fever, headache tiredness. anorexia or vomits) a bloodsample and oral temperature will be taken. and a standard questionnaire will be filled in. Thus, the events can be classified as malaria. gastrointestinal infection. respiratory tract infection. or other disease. according to rigorously detined criteria. Treatment will be administered according to routine guidelines. but if feasible. trial participants should receive priority attendance. All slides will be controlled at the reference laboratory in Peshawar.

Bioassays with laboratory bred mosquitoes will be conducted on a cohort of 5 to 10 randomly selected nets at monthly intervals. On each occasion. One assay will be performed in the upper part. one in the middle and one in the lower part of each net. The number of nets should depend on the number of test mosquitoes available but five nets should be the minimum. In addition, bioassays, following the same procedure. will be performed on two unused treated nets hung in a quiet room in the village. Bioassavs will also be pertormed on two nets which are known to be used correctly every night. This could help assess the compliance in the trial by the test households. If the residual effectiveness drops to a very low level within only a few months, all the nets should be retreated (a minimum level could be the mortality corresponding to that for a bioassay on netting treated with $0.1 \mathrm{~g}$ permethrin $/ \mathrm{m}^{-}$).

Data will have to be collected by inquiries and/or direct observation on when. where and how people sleep. All night human bait collections will then be made on a persons sleeping outdoors with and without a net, including the early evening before people go to bed. The number of persons needed must be determined in preliminary trials. These collections should be repeated at monthly intervals. at the same lunar
phase.

An additional study topic is the assessment of the risk of a person being bitten by mosquitoes when he sleeps near a person with a treated net, as compared to a situation where he sleeps near a person without a net. (The unprotected person could suffer from more bites due to a diverting effect of the net or he could receive less bites because of a killing effect of the net. Details of the study protocol will have to be worked out but a possibility could be to use two groups of two people working for a few hours on a number of successive nights. The groups would be located at a reasonable distance so as not to influence each, other for example 15-20 meters. In one group one person sleeps under a treated net while the second person remains awake on a bed nearby and
collects biting mosquitoes from his bare legs. In the other group the procedure is similar except that the sleeping person does not sleep under a net. On successive night the four persons are rotated to avoid a bias due to differences in personal attraction to mosquitoes.

Supplementary evaluation methods can still be considered. 
ANNEX 6, p.3

B. Evaluation of the effectiveness of insecticide treated "chadors"

According to information from various sources. many Afghans (and Pakistanis) sleep under "chadors" during the hot season. The "chadors". large blankets made of very thin and light semi-synthetic textile. are said to be used for protection from insects and dust and are wrapped completely around the body. enveloping both head and feet.

Insecticide treated chadors might appear to be an acceptable practical and effective mosquito control method. The chadors already seem to be widely used and would not require the extra investment needed for a mosquito net. In addition, the quantity of insecticide needed to treat a chador is much less than that for a mosquito net but this might be offset by the need for more frequent impregnations due to washing out of the insecticide. Before an entomological study is undertaken. it is needed to collect more information on the following topics:

- to what extent do Afghans sleep under chadors in the hot season.

- how are they used; are they also used at daytime; are they washed regularly

- would people accept insecticide impregnation of their chadors: would it be a safe method (toxicity from pyrethroid can be ruled out. but the prolonged skin-contact with the impregnated textile could theoretically lead to allergic reactions, reported anecdotically in people working with pyrethroids).

If the preliminary information is positive. an evaluation could be made of the protection offered by treated chadors. Of special importance would be an assessment of the residual effectiveness of insecticide applications in chadors used daily in the traditional way. In successive studies a person could sleep in the room under an untreated chador. a treated chador. and the same treated shador but without covering the head. After each study the mosquitoes are collected for an assessment of
feeding rate and mortality.

\section{Probing of the acceptability of impregnated bednets in Kunar
Province, Afghanistan}

Investigators

WHO FO statf, supported by MSF entomologist

\section{Aims}

While the controlled trial of impregnated bednets in Mardan District in NWFP is designed to assess the efficacy of this method for self-protection. numerous questions on acceptability and feasibility in Afghanistan will not be answered by it. If the results of the Mardan trial are positive, it will be advantageous, if some answers to these questions have been obtained. The issues are complex: should nets be distributed through "the bazar" or through a vertical network of health workers (vaccinators?). In both cases, there is a great risk of resale in Pakistan, where the buying-power is generally stronger than in
Afghanistan. 
ANNEX $6 . p .4$

\section{Methodology}

At the start of the transmission season. approximatelv 100 nets wiil be taken to Asadabad and Asmar: Health workers. mullahs and orher community leaders will be invited to a demonstration of their impregnation. and to meetings to discuss: acceptability. methods of distribution. impregnation. re-impregnation and sale.

The impregnated nets will then be sold at a subsidized price (still to be determined) to the persons invited. At the end of the transmission season, meetings will be held with the same persons. and their opinions on the same subjects will be recorded. in addition to their opinion on the effectiveness of the nets.

\section{Assessment of the therapeutic efficacy of chloroquine in falciparum
malaria in Afghanistan}

Objective and rationale

This exercise should be carried out by motivated doctors or exceptional ML workers who have good laboratory facilities at their disposal in Afghanistan. The aim is to assess the proportion of treatment failures (i.e. cases in which the clinical response to chloroquine is insatisfactory as a result of parasitological resistance to a standard dosage). If the rate of treatment failures in a given well-defined patient group exceeds $30-40 \%$. chloroquine should no longer be used as primary treatment of verified falciparum malaria in this
group.

\section{Methodology}

A series of falciparum malaria patients seeking medical attention are examined to exclude competing causes of fever; slide-result and temperature are recorded: standard chloroquine treatment over three days is administered at the clinic checking for vomiting; the patient is asked to come back if symptoms persist or recur: if this does not happen, the patient should come for slide and clinical control on Days 7 and 14 after start of chloroquine. On these days, a positive slide (asexual $P$.f.) proves resistance. and the additional presence of signs of malaria signifies treatment failure.

It should be made clear, that this kind of study is not routine management, but a monitoring tool. The more frequently it is used. the better will the doctors in Afghanistan and staff in Peshawar working vith malaria be able to immprove treatment guidelines. 


\section{ANNEX 7 Y}

ant

(106)

non

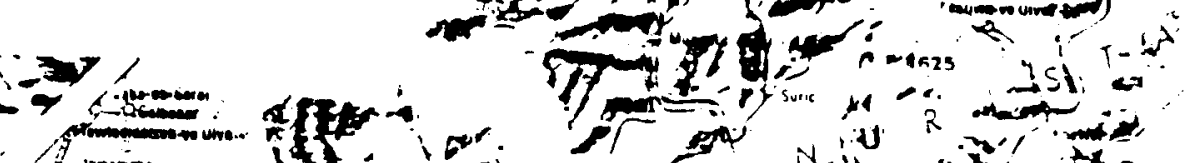

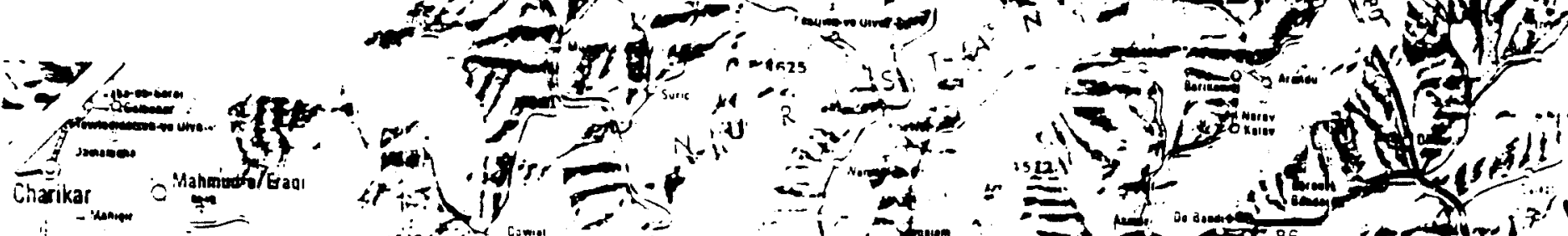

\section{$-a_{1}$}

KABUL

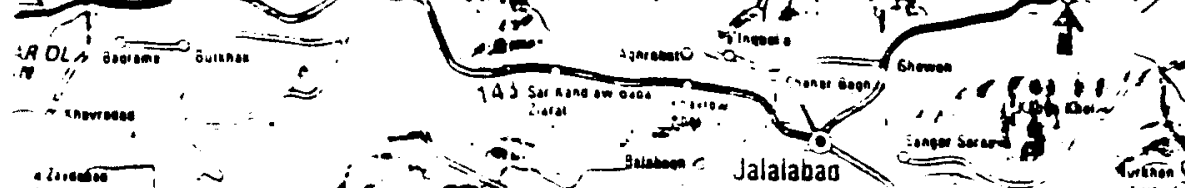

P=on sso,

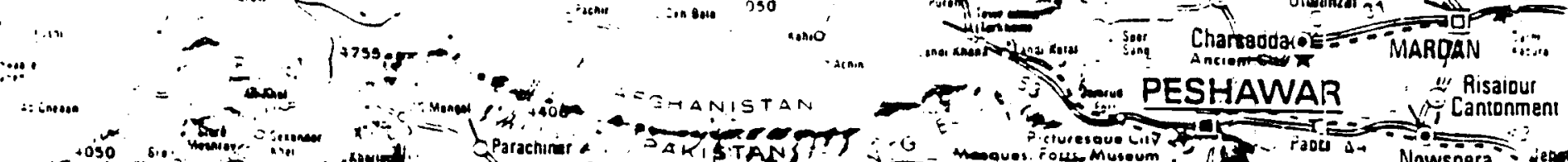

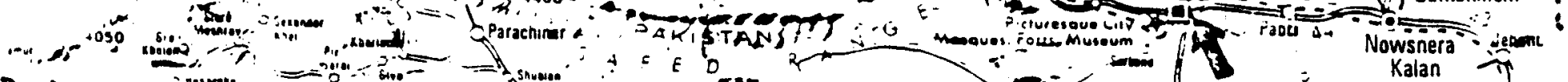

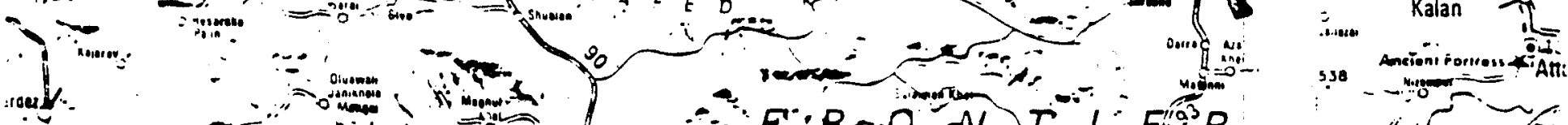

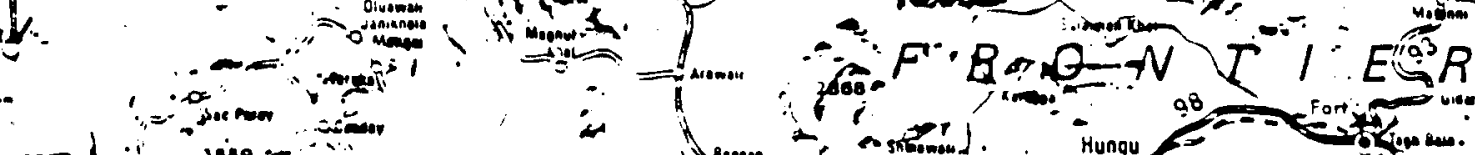

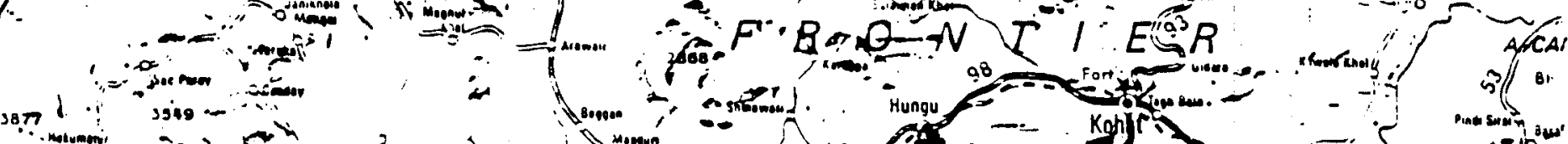
(n)

$\cdots$

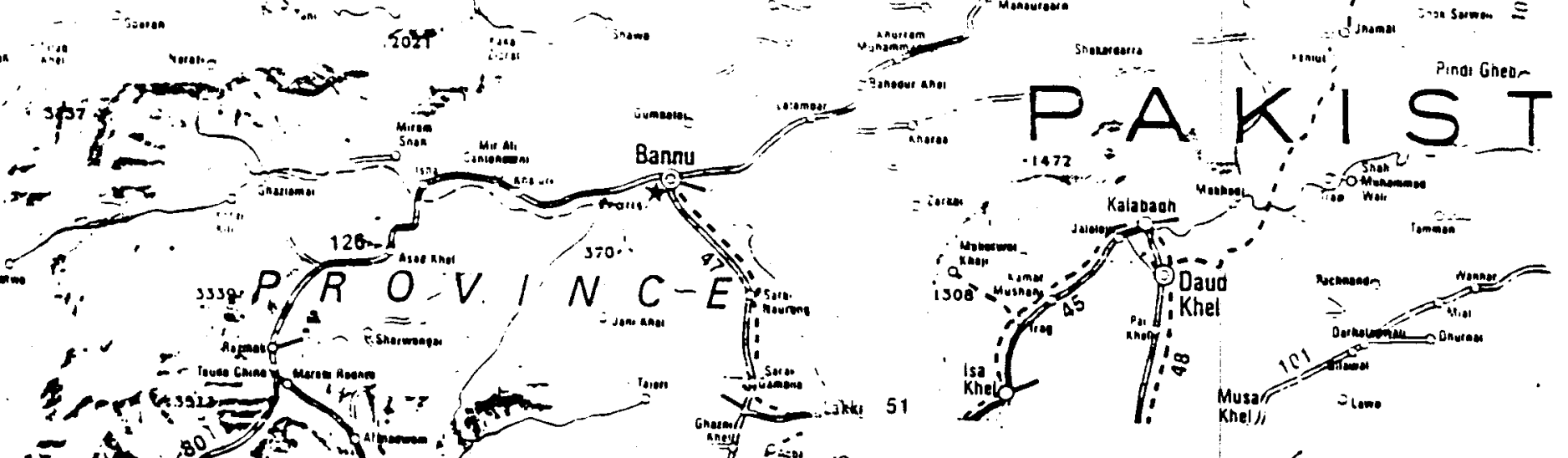

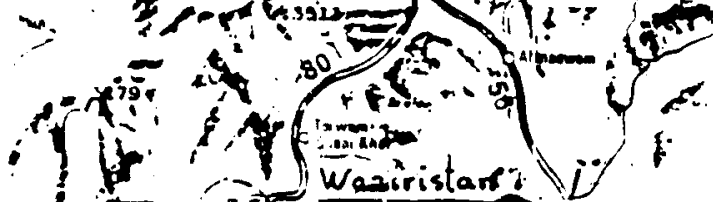
tit wezistaris

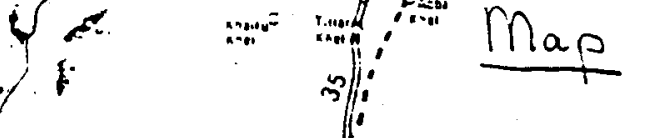
of North Wist Frontier Province in Pakistan and lunar Province in Olghanistan Bndicabed with an arrow are the places visited and

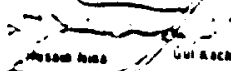
in

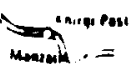
(1)

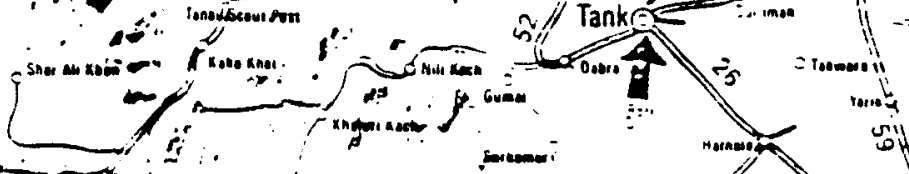

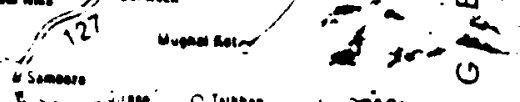

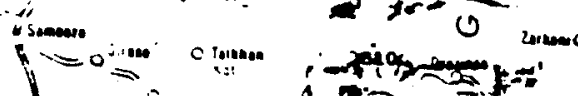
mentioned in the report 